\title{
Evaluation of exposures and respiratory health at a coffee roasting and packaging
}

facility

R. Reid Harvey, DVM, MPH Brie Hawley, MS, PhD

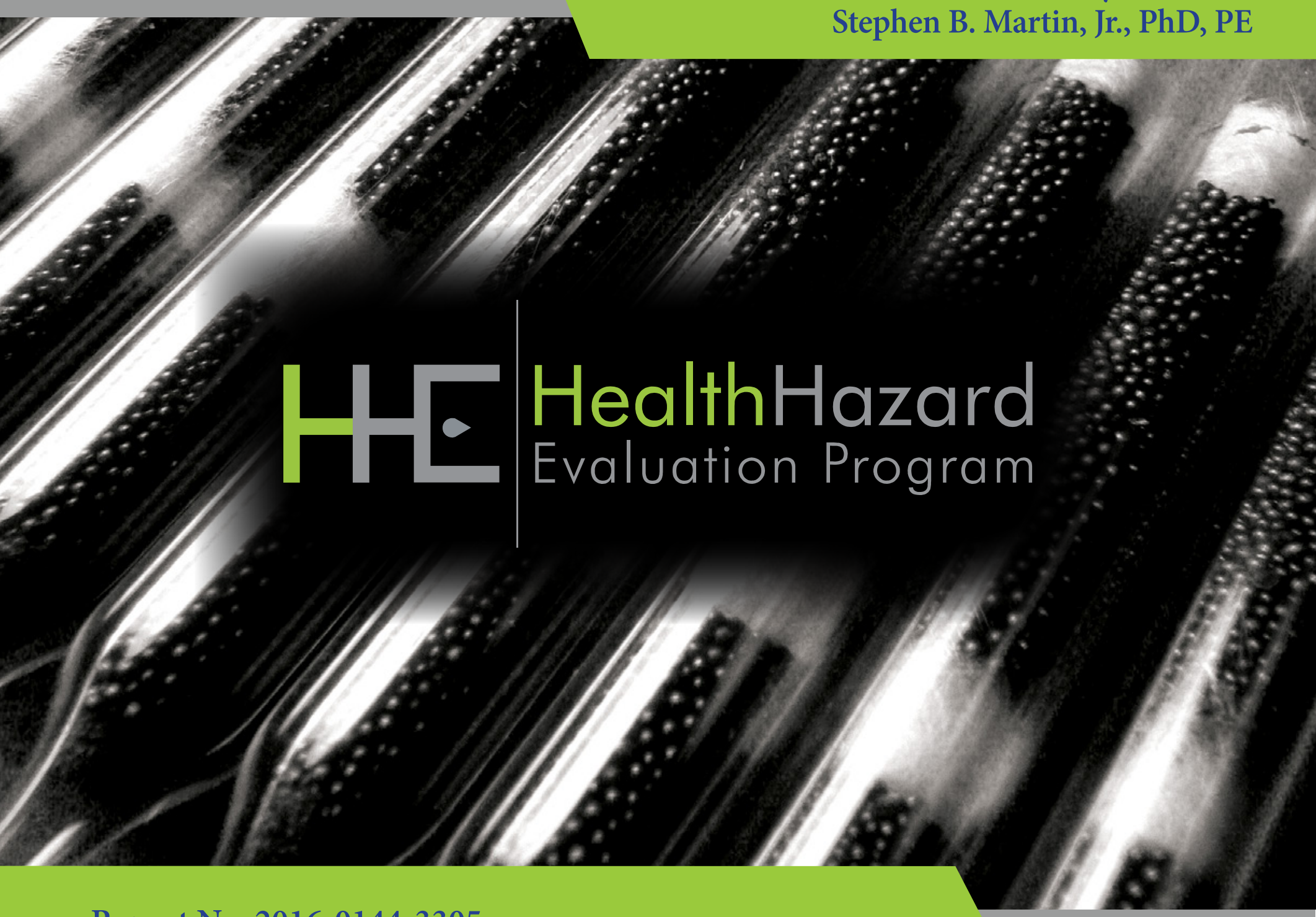

Report No. 2016-0144-3305

February 2018

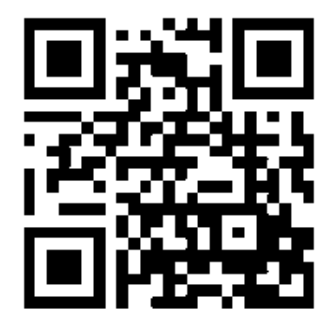

U.S. Department of Health and Human Services Centers for Disease Control and Prevention

National Institute for Occupational Safety and Health

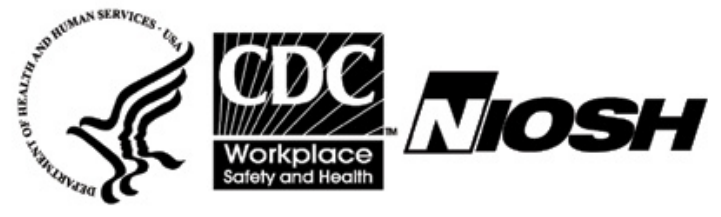




\section{Contents}

Highlights. i

Abbreviations .........................................v

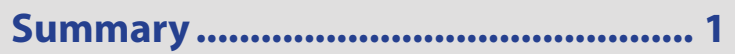

Introduction ........................................... 2

Background............................................. 2

Process Description ............................... 6

Methods ............................................. 8

Results ........................................... 13

Discussion ........................................... 18

Conclusions.......................................... 25

Recommendations............................ 26

Appendix A: Tables .............................. 31

References.......................................... 43

Acknowledgements............................ 53

The employer is required to post a copy of this report for 30 days at or near the workplace(s) of affected employees. The employer must take steps to ensure that the posted report is not altered, defaced, or covered by other material.

The cover photo is a close-up image of sorbent tubes, which are used by the HHE Program to measure airborne exposures. This photo is an artistic representation that may not be related to this Health Hazard Evaluation. 


\section{Highlights of this Evaluation}

The Health Hazard Evaluation Program of the National Institute for Occupational Safety and Health received a confidential request from employees of a coffee roasting and packaging facility regarding concerns about exposures to and health effects from diacetyl, smoke, and dust during coffee roasting and grinding.

\section{What We Did}

- We visited the coffee roasting and packaging facility on November 14-17, 2016 and November 29-December 1, 2016.

- We collected full-shift (hours), task (minutes), and instantaneous (seconds) air samples to measure concentrations of diacetyl, 2,3-pentanedione, and 2,3-hexanedione over multiple days.

- We collected roasted coffee beans (whole bean and ground) to measure their emission potential for diacetyl, 2,3-pentanedione, and 2,3-hexanedione.

- We measured real-time air levels of carbon monoxide and carbon dioxide.

- We assessed the ventilation system at the facility.

- We administered a health questionnaire to employees and performed medical tests.

\section{What We Found}

- On full-shift sampling, some employees (roaster operators, grinder operator, packaging operators, maintenance, green bean storage attendants, and employees with duties in both production and administrative areas) were exposed to diacetyl at concentrations above the recommended exposure limit of 5 parts per billion. The highest measured concentration of 24.5 parts per billion was measured on a packaging operator.

- Some employees (roaster operator and packaging operators) were also exposed to
We evaluated respiratory health and airborne exposures to the alpha-diketones diacetyl, 2,3-pentanedione, and 2,3-hexanedione, other volatile organic compounds, carbon monoxide, and carbon dioxide among employees at a coffee roasting and packaging facility. Some employees in the production area of the facility had full-shift exposures that exceeded the NIOSH recommended exposure limits for diacetyl and 2,3-pentanedione. In addition, air sampling during shortterm tasks identified several tasks (e.g., roasting coffee beans, grinding coffee beans, and packaging coffee) with higher exposures to alpha-diketones than other tasks. Air levels of carbon monoxide measured on employees with duties that included roasting and quality control grinding of roasted beans exceeded the NIOSH ceiling limit of 200 parts per million. Air levels of carbon monoxide near a grinder exceeded 200 parts per million. Eye and nose symptoms were the most commonly reported symptoms. Coughing and wheezing were the most common lower respiratory symptom reported. No participant had abnormal spirometry. We recommend installing local exhaust ventilation and training employees about work-place hazards. We also recommend instituting a medical monitoring program. 
concentrations above the recommended exposure limit for 2,3-pentanedione of 9.3 parts per billion. The highest measured full-shift concentration of 12.7 parts per billion was measured on a packaging operator.

- Levels of diacetyl in the air during short-term sampling were higher for tasks involving grinding roasted beans (24.0 parts per billion), roasting coffee beans (maximum 30.7 parts per billion), and packaging roasted coffee (maximum 27.1 parts per billion). Levels of 2,3-pentanedione in the air during short-term sampling were higher for tasks involving grinding roasted beans (14.1 parts per billion), and roasting coffee beans (maximum 27.0 parts per billion).

- Carbon monoxide levels were higher when workers were performing tasks near the roasters and grinders. Air levels of carbon monoxide measured on employees with duties that included roasting and quality control grinding of roasted beans exceeded the NIOSH ceiling limit of 200 parts per million. Carbon monoxide levels also exceeded 200 parts per million in the area near the FRAC grinder.

- All bulk samples of roasted coffee beans emitted diacetyl, 2,3-pentanedione, and 2,3-hexanedione.

- Eye and nose symptoms were the most commonly reported symptoms. Some employees reported their symptoms were caused or aggravated by green coffee dust, chaff, ground coffee, or smoke.

- Coughing and wheezing or whistling in the chest were the most commonly reported lower respiratory symptoms.

- None of the 37 participants had abnormal spirometry.

- Four (11\%) participants had high exhaled nitric oxide, a marker of allergic airways inflammation.

\section{What the Employer Can Do}

- Ensure employees understand potential hazards (e.g., diacetyl, 2,3-pentanedione, carbon monoxide, carbon dioxide, green and roasted coffee dust) in the workplace and how to protect themselves.

- Work with a ventilation engineer to determine if additional fresh, outdoor air can be supplied to the roasting and packaging areas. Also work with a ventilation engineer to ensure the production area is maintained under negative pressure compared with nonproduction spaces.

- Install local exhaust ventilation at all grinders to reduce air concentrations of alphadiketones.

- Ensure that hoppers filled with whole bean and ground coffee are covered to minimize the off-gassing of alpha diketones and carbon monoxide into the production space.

- Automate transfer of roasted beans or ground coffee, whenever possible, to minimize manual handling. 
- Minimize production tasks that require employees to place their heads inside roasted bean bins.

- Ensure that all doors between the production and non-production areas are kept closed.

- Limit the amount of time that non-production employees spend in the production area.

- Conduct follow-up air sampling to verify that the modifications have been effective in reducing exposures to below the recommended exposure limits.

- Consider additional engineering controls if follow-up air sampling demonstrates that exposures remain above the recommended exposure limits.

- Install a carbon monoxide monitor near the roasters, the quality control grinders near the roasters, and the three main grinders to alert employees if carbon monoxide levels exceed the ceiling limit of $200 \mathrm{ppm}$.

- Make N95 disposable filtering-face piece respirators available for voluntary use for protection against dust exposure, such as when emptying burlap bags of green beans into the storage silos, cleaning the exhaust system of chaff, emptying the chaff containers, or cleaning the green bean storage area.

- Encourage employees to report new, worsening, or ongoing respiratory symptoms to their personal healthcare providers and to a designated individual at the workplace.

- Institute a medical monitoring program for employees who work in the production area.

\section{What Employees Can Do}

- Use any local exhaust ventilation as instructed by your employer when it is installed.

- As much as possible, avoid placing your head directly above or inside roasted whole bean or ground coffee storage bins.

- Some employees may wish to use N95 disposable filtering-facepiece respirators for some tasks, such as when emptying burlap bags of green beans into the storage silos, when cleaning the exhaust system of chaff, when emptying the chaff containers, or when cleaning the green bean storage area.

- Report new, persistent, or worsening respiratory symptoms to your personal healthcare provider(s) and a designated individual at your workplace.

- Participate in any personal air sampling offered by your employer.

- Participate in your employer's medical monitoring program as instructed by your employer. 
This page left intentionally blank 


\section{Abbreviations}

\begin{tabular}{ll}
$\mu \mathrm{m}$ & Micrometer \\
$\mu \mathrm{g}$ & Microgram \\
${ }^{\circ} \mathrm{F}$ & degrees Fahrenheit \\
$\mathrm{ACGIH}^{\circ}$ & American Conference of Governmental Industrial Hygienists \\
$\mathrm{APF}$ & Assigned protection factor \\
$\mathrm{AX}$ & Area of reactance \\
$\mathrm{CFR}$ & Code of Federal Regulations \\
$\mathrm{CI}$ & Confidence interval \\
$\mathrm{CO}$ & Carbon monoxide \\
$\mathrm{CO}$ & Carbon dioxide \\
$\mathrm{COHb}$ & Carboxyhemoglobin \\
$\mathrm{COPD}$ & Chronic obstructive pulmonary disease \\
$\mathrm{DR} 5-\mathrm{R} 20$ & The difference between resistance at 5 and 20 Hertz \\
$\mathrm{EC}$ & Evaporative cooler \\
$\mathrm{FEV}$ & 1-second forced expiratory volume \\
$\mathrm{fpm}$ & Feet per minute \\
$\mathrm{Fres}$ & Resonant frequency \\
$\mathrm{FVC}$ & Forced vital capacity \\
$\mathrm{Hz}$ & Hertz \\
$\mathrm{kg} / \mathrm{m} 2$ & Kilogram per square meter \\
$\mathrm{kPa} /(\mathrm{L} / \mathrm{s})$ & Kilopascals per liter per second \\
$\mathrm{IDLH}$ & Immediately dangerous to life or health \\
$\mathrm{LPM}$ & Liters per minute \\
$\mathrm{LOD}$ & Limit of detection \\
$\mathrm{LOQ}$ & Limit of quantitation \\
$\mathrm{mg} / \mathrm{m}^{3}$ & Milligrams per cubic meter of air \\
$\mathrm{mL}$ & Milliliter \\
$\mathrm{mL} / \mathrm{min}$ & Milliliter per minute \\
$\mathrm{MUA}$ & Make-up air \\
$\mathrm{NHANES}$ & National Health and Nutrition Examination Survey \\
$\mathrm{NIOSH}$ & National Institute for Occupational Safety and Health \\
$\mathrm{OEL}$ & Occupational exposure limit \\
$\mathrm{OSHA}$ & Occupational Safety and Health Administration \\
$\mathrm{PEL}$ & Permissible exposure limit \\
$\mathrm{ppb}$ & Parts per billion \\
$\mathrm{ppm}$ & Parts per million \\
& \\
\hline &
\end{tabular}


QC Quality control

R5 Resistance at 5 Hertz

R20 Resistance at 20 Hertz

REL Recommended exposure limit

SMR Standardized morbidity ratios

$\mathrm{RH} \quad$ Relative humidity

STEL Short-term exposure limit

TLV $^{\oplus} \quad$ Threshold limit value

TVOC Total volatile organic compound

TWA Time-weighted average

VOC Volatile organic compound

X5 Reactance at 5 Hertz 


\section{Summary}

In July 2016, the National Institute for Occupational Safety and Health received a confidential request from employees of a coffee roasting and packaging facility. The request stated concerns about exposures to and health effects from diacetyl, smoke, and dust during coffee roasting and grinding. In November 2016, we conducted an industrial hygiene survey and ventilation assessment at the facility. The industrial hygiene survey consisted of the collection of air samples and bulk samples of coffee for the analysis of diacetyl, 2,3-pentanedione, and 2,3-hexanedione. Continuous monitoring instruments were used to monitor total volatile organic compounds, carbon monoxide, carbon dioxide, temperature, and relative humidity in specific areas and during tasks. We also measured levels of carbon monoxide in employees' exhaled breath and conducted a ventilation assessment. In November-December 2016, we conducted a medical evaluation of employees that consisted of a health questionnaire and medical tests.

Thirty-one of the 37 full-shift samples collected during the industrial hygiene survey exceeded the NIOSH recommended exposure limit for diacetyl of 5 parts per billion, with a maximum concentration of 24.5 parts per billion. Five of the 37 full-shift samples exceeded the NIOSH recommended exposure limit for 2,3-pentanedione of $9.3 \mathrm{ppb}$, with a maximum of 12.7 parts per billion. We identified jobs where some work tasks resulted in relatively higher air concentrations of diacetyl and 2,3-pentanedione than other tasks. Specifically, grinding roasted coffee beans, roasting coffee beans, and packaging roasted coffee were associated with higher diacetyl levels. We observed high instantaneous levels of diacetyl and 2,3-pentanedione during grinding. Air levels of carbon monoxide collected on employees with duties that included roasting coffee and quality control grinding of roasted beans exceeded the NIOSH ceiling limit of 200 parts per million. Carbon monoxide levels near the FRAC grinder exceeded 200 parts per million. Carbon dioxide levels were low throughout most of the facility.

Overall, the most commonly reported symptoms were associated with mucous membranes, specifically the eyes and nose. Some production employees reported their mucous membrane symptoms were caused or aggravated by green coffee dust, chaff, ground coffee or smoke. Coughing and wheezing or whistling in the chest were the most commonly reported lower respiratory symptoms. No participant had abnormal spirometry; four participants had high exhaled nitric oxide, a marker of allergic airways inflammation. We recommend installing local exhaust ventilation, and training employees about workplace hazards. We also recommend a medical monitoring program to identify any employees who may be developing work-related lung disease (e.g., asthma, obliterative bronchiolitis) and to help management prioritize interventions to prevent occupational lung disease. 


\section{Introduction}

In July 2016, the National Institute for Occupational Safety and Health (NIOSH) received a confidential employee request for a health hazard evaluation at a coffee roasting and packaging facility regarding potential worker exposures during coffee processing. In November 2016, we conducted a ventilation assessment and industrial hygiene survey at the facility. We collected area and personal breathing zone air samples for volatile organic compounds (VOCs), including diacetyl, 2,3-pentanedione, and 2,3-hexanedione. We also monitored and recorded carbon monoxide $(\mathrm{CO})$, carbon dioxide $\left(\mathrm{CO}_{2}\right)$, and total volatile organic compounds (VOCs). In November-December 2016, we conducted a medical survey.

\section{Background}

\section{Diacetyl and 2,3-Pentanedione}

Diacetyl (2,3-butanedione) and 2,3-pentanedione (acetyl propionyl) are VOCs known as alpha-diketones that are added as ingredients in food flavorings used in some food products such as microwave popcorn, bakery mixes, and flavored coffee [Day et al. 2011; Kanwal et al. 2006; Bailey et al. 2015]. Diacetyl, 2,3-pentanedione, other VOCs, and gases such as CO and $\mathrm{CO}_{2}$ are naturally produced and released during the coffee roasting process [Duling et al. 2016; Raffel and Thompson 2013; Daglia et al. 2007; Nishimura et al. 2003; Newton 2002]. Grinding roasted coffee beans produces a greater surface area for off-gassing (sometimes called degassing) of these compounds [Akiyama et al. 2003]. Often, coffee roasting facilities package newly roasted coffee in permeable bags or in bags fitted with one-way valves to allow the coffee to off-gas after it is packaged. Sometimes, newly roasted coffee is placed in bins or containers and allowed to off-gas before packaging.

NIOSH has recommended exposure limits (RELs) for diacetyl and 2,3-pentanedione in workplace air (Table 1) [NIOSH 2016]. The NIOSH objective in establishing RELs for diacetyl and 2,3-pentanedione is to reduce the risk of respiratory impairment (decreased lung function) and the severe irreversible lung disease obliterative bronchiolitis associated with occupational exposure to these chemicals. NIOSH RELs are intended to protect workers exposed to diacetyl or 2,3-pentanedione for a 45-year working lifetime. The REL for diacetyl is based on a quantitative risk assessment which necessarily contains assumptions and some uncertainty. Analytical limitations current at the time were taken into consideration in setting the REL for 2,3-pentanedione. The RELs should be used as a guideline to indicate when steps should be taken to reduce exposures in the workplace.

These exposure limits and the accompanying recommendations for control of exposures were derived from a risk assessment of flavoring-exposed workers. At an exposure equal to the diacetyl REL, the risk of adverse health effects is low. NIOSH estimated that less than 1 in 1,000 workers exposed to diacetyl levels of 5 parts per billion (ppb) as a time-weighted average (TWA) for 8 hours a day, 40 hours a week for a 45-year working lifetime would develop reduced lung function (defined as forced expiratory volume in one second $\left[\mathrm{FEV}_{1}\right]$ below the $5^{\text {th }}$ percentile) as a result of that exposure. NIOSH predicted that around 1 in 
10,000 workers exposed to diacetyl at 5 ppb for a 45-year working lifetime would develop more severe lung function reduction $\left(\mathrm{FEV}_{1}\right.$ below $60 \%$ predicted, defined as moderately severe by the American Thoracic Society [Pellegrino et al. 2005]). Workers exposed for less time would be at lower risk for adverse lung effects.

\section{2,3-Hexanedione}

2,3-Hexanedione is also an alpha-diketone that is sometimes used as a substitute for diacetyl and is produced naturally during coffee roasting. In a study using animals, there was some evidence that 2,3-hexanedione might also damage the lungs, but it appeared to be less toxic than diacetyl and 2,3-pentanedione [Morgan et al. 2016]. There are no established occupational exposure limits for 2,3-hexanedione.

\section{Carbon Monoxide and Carbon Dioxide}

$\mathrm{CO}$ and $\mathrm{CO}_{2}$ are gases produced by combustion. They are also produced as a result of reactions that take place during coffee roasting. These gases are released during and after roasting and grinding by a process called off-gassing [Anderson et al. 2003]. High exposures to $\mathrm{CO}$ and $\mathrm{CO}_{2}$ can cause headache, dizziness, fatigue, nausea, altered mentation, rapid breathing, impaired consciousness, coma, and death [Newton 2002; Nishimura et al. 2003; Langford 2005; CDC 2013a; Raffel and Thompson 2013; Rose et al. 2017]. Occupational exposure limits for $\mathrm{CO}$ and $\mathrm{CO}_{2}$ are listed in Table 1 .

\section{Exposure Limits}

We utilize mandatory (legally enforceable) and recommended occupational exposure limits (OELs) when evaluating workplace hazards. OELs have been developed by federal agencies and safety and health organizations to prevent adverse health effects from workplace exposures.

\section{Occupational Safety and Health Administration (OSHA)}

The U.S. Department of Labor's OSHA permissible exposure limits (PELs) are legal limits that are enforceable in workplaces covered under the Occupational Safety and Health Act. OSHA PELs represent the legal maximum for a TWA exposure to a physical or chemical agent over a work shift [OSHA 2016]. OSHA short-term exposure limits (STELs) are the legal maximum average exposure for a 15-minute time period. Some chemicals also have an OSHA ceiling value which represent levels that must not be exceeded at any time. Currently, there are no PELs for diacetyl, 2,3-pentanedione, or 2,3-hexanedione. For substances for which an OSHA PEL has not been issued, violation of the OSHA General Duty Clause can be considered using available occupational exposure references and recommendations [OSHA 1993; OSHA 2003], such as the American Conference of Governmental Industrial Hygienists $\left(\mathrm{ACGIH}^{\circledR}\right)$ Threshold Limit Values $\left(\mathrm{TLVs}^{\circledR}\right)$ and NIOSH RELs.

\section{American Conference of Governmental Industrial Hygienists $\left(\mathrm{ACGIH}^{\circledR}\right)$}

$\mathrm{ACGIH}^{\circledR}$ is a professional, not-for-profit scientific association that reviews existing published, peer-reviewed scientific literature and publishes recommendations for levels of substances in air based on an 8-hour workday and 40-hour workweek. These recommendations are called threshold limit values $\left(\mathrm{TLVs}^{\circledR}\right)$ [ACGIH 2017a]. ACGIH $^{\circledR}$ TLVs $^{\circledR}$ 
are not standards; they are health-based guidelines derived from scientific and toxicological information. ACGIH ${ }^{\circledR}$ provides $\mathrm{TLV}^{\circledR}$-TWA guidelines that are levels that should not be exceeded during any 8-hour workday of a 40-hour workweek. ACGIH ${ }^{\circledR}$ also provides TLV $^{\circledR}$ STEL guidelines which are 15-minute exposure levels that should not be exceeded during a workday. Exposures above the TLV ${ }^{\circledR}$-TWA but less than the TLV ${ }^{\circledR}$-STEL should be (1) less than 15 minutes, (2) occur no more than four times a day, and (3) be at least 60 minutes between exposures [ACGIH ${ }^{\circledR}$ 2017a]. Additionally, ACGIH ${ }^{\circledR}$ provides TLV $^{\circledR}$-Ceiling values which are levels that should not be exceeded at any time during a work shift. The $\mathrm{ACGIH}^{\circledR}$ $\mathrm{TLV}^{\circledR}$-TWA for diacetyl is $10 \mathrm{ppb}$. The $\mathrm{TLV}^{\circledR}-\mathrm{STEL}$ for diacetyl is $20 \mathrm{ppb}$. Currently, there is no $\mathrm{TLV}^{\circledR}$-TWA or $\mathrm{TLV}^{\circledR}$-STEL for 2,3-pentanedione. $\mathrm{ACGIH}^{\circledR}$ has placed 2,3-pentanedione on the 2017 list of Chemical Substances and Other Issues Under Study [ACGIH ${ }^{\circledR}$ 2017b].

National Institute for Occupational Safety and Health (NIOSH) NIOSH provides RELs as TWA concentrations that should not be exceeded over an 8 or 10-hour work shift, during a 40-hour workweek [NIOSH 2010]. RELs are intended to be protective over a 45-year working lifetime. NIOSH also provides STELs which are 15-minute TWA exposures that should not be exceeded at any time during a workday [NIOSH 2010]. Some chemicals have ceiling values which are concentrations that should not be exceeded at any time [NIOSH 2010]. For some chemicals, NIOSH has established an Immediately Dangerous to Life or Health (IDLH) value. An IDLH value is a concentration of an air contaminant that can cause death or immediate or delayed permanent adverse health effects, or prevent escape from such an environment. Currently, NIOSH has RELs and STELs for diacetyl and 2,3-pentanedione. NIOSH does not have a REL or a STEL for 2,3-hexanedione. NIOSH does not have ceiling limits or IDLH values for diacetyl, 2,3-pentanedione, or 2,3-hexanedione.

For diacetyl and 2,3-pentanedione, the NIOSH RELs are $5.0 \mathrm{ppb}$ and $9.3 \mathrm{ppb}$, respectively, as a TWA for up to an 8-hour workday during a 40-hour workweek (Table 1). The NIOSH STELs are $25 \mathrm{ppb}$ for diacetyl and $31 \mathrm{ppb}$ for 2,3-pentanedione [NIOSH 2016]. The NIOSH exposure limits do not differentiate between natural and synthetic chemical origin of diacetyl or 2,3-pentanedione. Although the NIOSH exposure limit for 2,3-pentanedione is above that of diacetyl, 2,3-pentanedione has been shown to be as hazardous as diacetyl [Hubbs et al. 2012; Morgan et al. 2012]. The hazard potential probably increases when these chemicals occur in combination with each other; having exposure to chemicals with the same functional alpha-diketone group and effect on the same system or organ (e.g., lungs) can result in additive effects [ACGIH 2017a]. The NIOSH REL is higher for 2,3-pentanedione than for diacetyl largely because analytic measures were not available in a validated OSHA method to detect 2,3-pentanedione at lower levels. In addition to the REL, NIOSH also recommends an action level for diacetyl of $2.6 \mathrm{ppb}$ to be used with exposure monitoring in an effort to ensure employee exposures are routinely below the diacetyl REL. When exposures exceed the action level, employers should take corrective action (i.e., determine the source of exposure, identify methods for controlling exposure) to ensure that exposures are maintained below the NIOSH REL for diacetyl [NIOSH 2016]. 
Table 1. Exposure limits for compounds sampled during the NIOSH survey, November 2016.

\begin{tabular}{|l|c|c|c|c|c|c|}
\hline \multirow{2}{*}{ Compound } & OSHA* & \multicolumn{2}{|c|}{ ACGIH } & \multicolumn{3}{c|}{ NIOSH } \\
\cline { 2 - 7 } & PEL & TLV & STEL & REL & STEL & IDLH \\
\hline Diacetyl & - & $10 \mathrm{ppb}$ & $20 \mathrm{ppb}$ & $5 \mathrm{ppb} \dagger$ & $25 \mathrm{ppb}$ & - \\
\hline 2,3-Pentanedione & - & - & - & $9.3 \mathrm{ppb} \dagger$ & $31 \mathrm{ppb}$ & - \\
\hline 2,3-Hexanedione & - & - & - & - & - & $40,000 \mathrm{ppm}$ \\
\hline Carbon dioxide & $5,000 \mathrm{ppm}$ & $5,000 \mathrm{ppm}$ & $30,000 \mathrm{ppm}$ & $5,000 \mathrm{ppm}$ & $30,000 \mathrm{ppm}$ & $\begin{array}{c}200 \mathrm{ppm} \\
\text { Carbon monoxide } \S\end{array}$ \\
\hline
\end{tabular}

Note: OSHA=Occupational Safety and Health Administration; ACGIH=American Conference of Governmental Industrial Hygienists; NIOSH=National Institute for Occupational Safety and Health; $P E L=$ permissible exposure limit; $S T E L=$ short-term exposure limit; $T L V=$ threshold limit value; $R E L=$ recommended exposure limit; IDLH=immediately dangerous to life or health; $\mathbf{m g} / \mathbf{m}^{3}=$ milligram per cubic meter; ppb=parts per billion; ppm=parts per million; "_"“=no exposure limit available. *There are no OSHA STEL or IDLH values for the compounds in the table.

$\dagger$ The NIOSH RELs for diacetyl and 2,3-pentanedione are time-weighted averages for up to an 8- or 10hour day, during a 40-hour workweek.

\$ACGIH does not have a TLV for inhalable or respirable dust but does provide guidelines for inhalable and respirable dust; ACGIH guidelines suggests airborne concentrations be kept below $3 \mathrm{mg} / \mathrm{m}^{3}$ for respirable particles and $10 \mathrm{mg} / \mathrm{m}^{3}$ for inhalable particles.

§OSHA and NIOSH limits are designed for occupational exposure measurements in manufacturing and other trades that have potential sources of carbon dioxide or carbon monoxide (e.g., coffee roasting, welding, vehicle exhaust, diesel engine exhaust). Typical levels of carbon monoxide in offices are 0-5 ppm. In office settings, carbon dioxide generally should not be greater than $700 \mathrm{ppm}$ above outdoor carbon dioxide levels; this typically corresponds to indoor concentrations below $1200 \mathrm{ppm}$.

qThis is the NIOSH ceiling exposure limit for carbon monoxide. A ceiling concentration should not be exceeded at any time.

\section{Obliterative Bronchiolitis}

Obliterative bronchiolitis is a serious, often disabling, lung disease that involves scarring of the very small airways (i.e., bronchioles). Symptoms of this disease may include cough, shortness of breath on exertion, and/or wheeze, that do not typically improve away from work [NIOSH 2012]. Occupational obliterative bronchiolitis has been identified in flavoring manufacturing workers and microwave popcorn workers who worked with flavoring chemicals or butter flavorings [Kreiss 2013; Kim et al. 2010; Kanwal et al. 2006]. It has also been identified in employees at a coffee roasting and packaging facility that produced unflavored and flavored coffee [CDC 2013b]. A NIOSH health hazard evaluation at that facility found diacetyl and 2,3-pentanedione concentrations in the air that were concerning (range: $4.3 \mathrm{ppb}$ to $166 \mathrm{ppb}$ diacetyl; $<5.2 \mathrm{ppb}$ to $199 \mathrm{ppb} 2,3$-pentanedione) and identified three sources: 1) flavoring chemicals added to roasted coffee beans in the flavoring area; 2) grinding unflavored roasted coffee beans and packaging unflavored ground and whole bean roasted coffee in a distinct area of the facility, and 3) storing roasted coffee in hoppers, on a mezzanine above the grinding/packaging process, to off-gas [Duling et al. 2016]. At the time of the health hazard evaluation, workers had excess shortness of breath and obstruction on spirometry, both consistent with undiagnosed lung disease. Respiratory illness was associated with exposure and not limited to the flavoring areas [Bailey et al. 2015]. However, 
all workers who were diagnosed with obliterative bronchiolitis had worked in the flavoring area. To date, no cases of obliterative bronchiolitis have been reported in workers at coffee roasting and packaging facilities that produce only unflavored coffee.

\section{Work-related Asthma}

Work-related asthma refers to asthma that is brought on by ("occupational asthma") or made worse by ("work-exacerbated asthma" or "work-aggravated asthma") workplace exposures [Tarlo 2016; Tarlo and Lemiere 2014; OSHA 2014; Henneberger et al. 2011]. It includes asthma due to sensitizers, which cause disease through immune (allergic) mechanisms, and asthma due to irritants, which cause disease through non-immune mechanisms. Symptoms of work-related asthma include episodic shortness of breath, cough, wheeze, and chest tightness. The symptoms may begin early in a work shift, towards the end of a shift, or hours after a shift. They generally, but do not always, improve or remit during periods away from work, such as on weekends or holidays.

Green and roasted coffee dust and castor beans (from cross-contamination of bags used to transport coffee) are known risk factors for occupational asthma [Figley and Rawling 1950; Karr et al. 1978; Zuskin et al. 1979, 1985; Thomas et al. 1991]. Persons who become sensitized (develop an immune reaction) to coffee dust can subsequently react to relatively low concentrations in the air. Others may experience irritant-type symptoms from exposure to coffee dust [Oldenburg et al. 2009].

\section{Process Description}

In November 2016, the coffee roasting and packaging facility had roughly 150 total employees, with approximately 50 of those employees in the roasting and production sub teams. The employees were not represented by a union. The facility was located in a building shared with a café and had been at this location since 2000. At the coffee roasting and packaging facility, the production area was approximately 48,000 square feet in size. Roughly 36,000 pounds of coffee was roasted and packaged per day, and approximately $40 \%$ of the coffee produced was ground coffee. The facility received and stored a two month supply of green coffee, or approximately 1.5 million pounds on site. Green beans were stored in burlap bags in a designated green bean storage area.

To prepare a batch for roasting, a roaster operator weighed the desired amount of green beans before adding them to the roaster. Three roasters were operating during our visit. Two roasters could hold 240 pounds of coffee beans, and one roaster could hold up to 460 pounds of coffee beans. The company had plans to bring in a fourth roaster that would have a 660-pound capacity. When ready, the roaster operator dropped the green beans into the roaster. The beans were heated to a specific temperature and for a specific time period for the desired roast. Time and temperature varied between different types of roasts. On average, roasts lasted 14 minutes to 16 minutes. Occasionally, the roaster operator would pull a small sample of beans from the roaster to check the color of the beans. At the end of each cycle, the roaster operator emptied the roasted beans into a cooling bin where they were agitated 
by a rotating arm. The cooling bins at both of the 240 pound capacity roasters utilized a downdraft exhaust system that pulled air downward past the roasted beans to accelerate cooling. The 460-pound capacity roaster was equipped with an enclosed cooling bin and an up-draft exhaust system that pushed air up from the bottom of the bin, over the roasted beans to accelerate cooling. The downdraft and enclosed up-draft systems pulled exhaust through the roaster, the afterburners, and then to the outside through a ventilation duct. The roaster operator monitored the roasting equipment throughout the roasting and cooling process. After each roast, the roaster operator would collect a small sample of roasted beans from the cooling bin and use the quality control (QC) grinders to assess the color and quality of the roasted beans. After cooling, the roasted beans were dispensed from the cooling bin by a pneumatic siphon system through a destoner and then dispensed into a large metal rolling hopper. The roaster operator then manually moved the rolling hoppers to a storage area until needed for further processing, including grinding and packaging. The roasters were routinely cleaned to remove accumulated chaff from the exhaust lines. A quality control (QC) technician periodically brewed roasted coffee in a separate quality control room to assess product quality and taste.

In the packaging area, orders were completed using packaging lines that included: the can line, that packaged anywhere from 11-ounce to 14-ounce cans or 28.5-ounce cans; the capsule line that packaged ground coffee; the GL11 hand pack bag line that packaged ground or whole bean coffee; the FRAC lines, which included the Matrix and Hayssen lines, that packaged ground coffee; the G18 line that packaged 5-pound bags of whole bean coffee; the G14C line that packaged 8-ounce to 12-ounce bags, and occasionally 1.5-pound bags of whole bean or ground coffee; the G14 line that packaged 12-ounce bags of whole bean or ground coffee; and the GL14 line that packaged 1.5 pounds of whole bean or ground coffee. Three grinders were used to grind coffee. The 669 grinder could grind up to 600 pounds per hour and was shared by the can line, capsules line, and hand packaging lines. The FRAC grinder could grind 700 pounds per hour and was used by the 2 FRAC lines. Grinder 1 was used by the GL14 and G14C lines and could grind up to 700 pounds per hour. After packaging, bags and cans of coffee were stored in cardboard cases in the coffee finished goods area for one to two weeks before shipping out.

A breakroom area and offices were located in the space adjacent to the production floor. Administrative offices were located in two separate locations (upper level and lower level) in the same building.

\section{Personal Protective Equipment}

Employees were not required to wear a company uniform. Prior to the our survey in November 2016, the company hired a consultant to conduct personal air monitoring for diacetyl and 2,3-pentanedione exposures at this facility. Based on the previous air sampling results, roaster operators were required to wear half-mask respirators equipped with organic vapor cartridges. A written respiratory protection program was in place for employees who performed job duties at the roasters. 


\section{Methods}

In November 2016, we conducted our initial visit of the facility. We held an opening meeting with management and employees, collected bulk samples and air samples, and performed a ventilation assessment. At the conclusion of our site visit, we held a closing meeting with management and employees. We visited the facility again November-December 2016 to conduct a medical survey.

We had the following objectives for the health hazard evaluation:

1. Measure employees' exposure to diacetyl, 2,3-pentanedione, and 2,3-hexanedione during coffee processing;

2. Identify process areas or work tasks associated with emissions of diacetyl, 2,3-pentanedione, and 2,3-hexanedione;

3. Measure levels of $\mathrm{CO}$ and $\mathrm{CO}_{2}$ throughout the facility;

4. Measure CO levels in employees' exhaled breath;

5. Assess ventilation systems and their effect on exposure levels;

6. Determine if employees had mucous membrane, respiratory, or systemic symptoms and the proportion of those symptoms that were work-related or aggravated by work;

7. Determine if employees had abnormal lung function tests; and

8. Compare employees' prevalence of respiratory symptoms and healthcare providerdiagnosed asthma to expected levels based on general population values.

\section{Industrial Hygiene Survey}

\section{Sampling Times for Alpha-Diketones}

We designed the sampling strategy to assess full-shift exposures and to identify tasks and processes that were the greatest contributors to worker exposure to alpha-diketones. Sampling was conducted over multiple days during each site visit. For diacetyl, 2,3-pentanedione, and 2,3-hexanedione, air samples were collected over seconds, minutes, and hours. Samples collected over hours can help determine average concentrations that can be compared to the NIOSH RELs for diacetyl and 2,3-pentanedione. These average concentrations might not tell us about short-term peak exposures that could be relevant to respiratory health, particularly when tasks are repeated multiple times per day. Therefore, during particular tasks, we collected air samples over several minutes. We also conducted instantaneous sampling over seconds to help identify point sources of alpha-diketones.

Air Sampling and Analysis Using Modified Occupational Safety and Health Administration (OSHA) Methods 1013/1016

We collected personal and area air samples for diacetyl, 2,3-pentanedione, and 2,3-hexanedione on silica gel sorbent tubes during both industrial hygiene surveys over multiple days. The samples were collected and analyzed according to the modified OSHA 
sampling and analytical Methods 1013/1016 [OSHA 2008; OSHA 2010; LeBouf and Simmons 2017]. In accordance with the two methods, two glass silica gel sorbent tubes were connected by a piece of tubing and inserted into a protective, light-blocking cover. The tubes were connected in series to a sampling pump pulling air through the tubes at a flow rate of 50 milliliters per minute $(\mathrm{mL} / \mathrm{min})$. The sampling setup was attached to an employee's breathing zone or placed in an area basket in various places throughout the facility. For full-shift sampling, we collected two consecutive 3-hour samples and calculated the TWA concentration from the two samples, assuming that the total 6-hour monitoring results reflected a full work shift (8-hour) TWA exposure. Although this may introduce some error, it is a conservative approach that is more protective of employees than the alternative assumption of no exposure during the last two hours of the shift. We refer to these samples as "full-shift samples" throughout this report. We also collected short-term task based samples in the same manner, but the sampling pump flow rate was $200 \mathrm{~mL} / \mathrm{min}$ as detailed in OSHA Methods 1013 and 1016 [OSHA 2008; 2010]. Sampling times were dependent on the duration of the task being performed.

Analyses of the samples were performed in the NIOSH Respiratory Health Division's Organics Laboratory. The samples were extracted for one hour in 95\% ethanol:5\% water containing 3-pentanone as an internal standard. Samples from both visits were analyzed using an Agilent 7890/7001 gas chromatograph/mass spectrometer system operated in selected ion monitoring mode for increased sensitivity compared to the traditional flame ionization detector used in OSHA Methods 1013 and 1016 [LeBouf and Simmons 2017].

The limit of detections (LOD) for the alpha-diketone sampling results were the lowest mass that our instruments could detect above background and was a criterion used to determine whether to report a result from a sample. The limit of quantitation (LOQ) was the lowest mass that could be reported with precision; we have a greater confidence in the reported result if it is above the LOQ. The LODs were 0.01 micrograms per sample $(\mu \mathrm{g} / \mathrm{sample})$ for diacetyl, 2,3-pentanedione, and 2,3-hexanedione. These equate to 0.3 parts per billion (ppb) for diacetyl, $0.2 \mathrm{ppb}$ for 2,3-pentanedione, and $0.2 \mathrm{ppb}$ for 2,3-hexanedione for a typical full-shift TWA air sample but will vary depending on the volume of air collected during the sampling period. The LODs for task samples are generally higher than typical LOD values for full-shift samples since the air volumes collected during task samples are lower. When the values presented in the report are from samples below the LOD they are denoted by a " $<$ " symbol.

\section{Air Sampling and Analysis Using Evacuated Canisters}

We collected area full-shift air samples and instantaneous task-based and source air samples for VOCs including diacetyl, 2,3-pentanedione, and 2,3-hexanedione using evacuated canisters. We also collected instantaneous air samples before and after the work shift to determine if air concentrations of alpha-diketones increased over a work shift. The evacuated canister sampling setup consisted of a 450-mL evacuated canister equipped with an instantaneous flow controller that was designed for a short sampling duration (less than 30 seconds). Instantaneous samples were taken by opening the evacuated canister to grab a sample of air to help identify point sources of alpha-diketones. For task-based air samples, a 
NIOSH employee placed the inlet of the flow controller by the employee's personal breathing zone as they performed their work task to replicate exposure. For source air samples, a NIOSH employee placed the inlet of the flow control directly at the source of interest.

The canister air samples were analyzed using a pre-concentrator/gas chromatograph/ mass spectrometer system pursuant to a published method validation study [LeBouf et al. 2012], with the following modifications: the pre-concentrator was a Model 7200 (Entech Instruments, Inc., Simi Valley, CA), and six additional compounds, diacetyl, 2,3-pentanedione, 2,3-hexanedione, acetaldehyde, acetonitrile, and styrene, were included. At present, this canister method is partially validated [LeBouf et al. 2012] and not considered the standard method. The LODs were $0.78 \mathrm{ppb}$ for diacetyl, $1.08 \mathrm{ppb}$ for 2,3-pentanedione, and $1.92 \mathrm{ppb}$ for 2,3-hexanedione based on a three-times dilution factor. However, LODs are dependent on the pressure inside each canister after the samples have been collected, and they may be higher or lower than typical LOD values.

\section{Bulk Sampling and Headspace Analysis}

We used 50-mL sterile polypropylene centrifuge tubes to collect approximately $40-\mathrm{mL}$ bulk samples of roasted coffees (whole bean). For headspace analysis of alpha-diketones, we transferred 1 gram of solid bulk material into a sealed $40-\mathrm{mL}$ amber volatile organic analysis vial and let it rest for 24 hours at room temperature $\left(70^{\circ} \mathrm{F}\right)$ in the laboratory. Then $2 \mathrm{~mL}$ of headspace air was transferred to a $450-\mathrm{mL}$ canister and pressurized to approximately 1.5 times atmospheric pressure. Using the canister analysis system, the concentrations were calculated in ppb of analytes in the headspace as an indicator of emission potential.

\section{Real-time (Continuous) Air Sampling}

We used RAE Systems (San Jose, CA) ppbRAE 3000 (Model \#PGM-7340) monitors to measure concentrations of total VOCs in the air. The ppbRAE has a non-specific photoionization detector that responds to chemicals with ionization potentials below the energy of the lamp. This sampling was conducted to identify areas where coffee could be releasing total VOCs. Areas where higher concentrations of total VOCs are measured help indicate areas where sampling to characterize specific exposures to alpha-diketones may be necessary. We also collected real-time measurements of $\mathrm{CO}_{2}, \mathrm{CO}$, temperature, and relative humidity (RH) using TSI Incorporated (Shoreview, MN) VelociCalc Model 9555-X MultiFunction Ventilation Meters equipped with Model 982 IAQ probes.

We also continuously measured employee personal exposures to $\mathrm{CO}$ using a Dräger Pac ${ }^{\circledR}$ 7000 personal single gas detector (Lübeck, Germany). The Dräger Pac® 7000 was placed near the breathing zone of employees and worn by employees while they performed their work duties.

\section{Exhaled CO Measurements}

We asked employees to perform a carboxyhemoglobin $(\mathrm{COHb})$ test one or more times throughout their shift to measure $\mathrm{CO}$ levels in their exhaled breath. This test helps determine if employees are exposed to elevated levels of CO. Employees were asked to hold their breath for 15 seconds and then exhale through a mouthpiece into a $\mathrm{CO}$ monitor. The device 
then calculated an estimate of carboxyhemoglobin in blood. We asked participants when they last smoked cigarettes or used tobacco products. Tobacco smoke from cigarettes, cigars, and pipe tobacco contains $\mathrm{CO}$ and can cause an increase in exhaled $\mathrm{CO}$.

\section{Ventilation Assessment}

The size and layout of mechanical ventilation systems did not allow us to take airflow measurements. However, we did a visual assessment of all ventilation components associated with the coffee roasting and grinding production space at the facility. When available, the make, model, and other key information on mechanical systems serving the production space was also collected.

\section{NIOSH Medical Survey}

\section{Participants}

We invited all current employees to participate in the medical survey at the workplace on November 29-December 1, 2016. Participation was voluntary; written informed consent was obtained from each participant before testing. The survey included, in the order performed, a medical and work history questionnaire, quantification of exhaled nitric oxide, impulse oscillometry, spirometry, and if indicated the administration of a bronchodilator with repeat impulse oscillometry and spirometry. We mailed participants their individual reports explaining their breathing test results and recommended each participant provide the information to their personal physician.

\section{Questionnaire}

We used an interviewer-administered computerized questionnaire to ascertain symptoms and diagnoses, work history at this coffee roasting and packaging facility and other coffee or flavoring companies, and cigarette smoking history. Questions on respiratory health were derived from five standardized questionnaires, the European Community Respiratory Health Survey [Burney et al. 1994; ECRHS 2014], the American Thoracic Society adult respiratory questionnaire (ATS-DLD-78) [Ferris 1978], the International Union Against Tuberculosis and Lung Disease [Burney and Chinn 1987; Burney et al. 1989], and the Third National Health and Nutrition Examination Survey (NHANES III) [CDC 1996] and NHANES 2007-2012 questionnaires [CDC 2017a]. Some of the questions appeared on more than one of the standardized questionnaires. We also supplemented our questionnaire with additional respiratory and systemic symptom questions.

\section{Spirometry}

The purpose of the spirometry test was to determine a person's ability to move air out of their lungs. Test results were compared to expected normal values. The test included three measurements or calculations: 1) forced vital capacity (FVC), (the total amount of air the participant can forcefully blow out after taking a deep breath), 2) $\mathrm{FEV}_{1}$ (the amount of air that the participant can blow out in the first second of exhaling), and 3 ) the ratio of $F E V_{1}$ to FVC. We used American Thoracic Society criteria for acceptability and repeatability [Miller et al. 2005].

We used a volume spirometer (dry rolling seal spirometer) to measure exhaled air volume 
and flow rates. We used equations for predicted values and lower limits of normal derived from NHANES III data to define abnormal spirometry [Hankinson et al. 1999]. We defined obstruction as an $\mathrm{FEV}_{1} / \mathrm{FVC}$ ratio less than the lower limit of normal with $\mathrm{FEV}_{1}$ less than the lower limit of normal; restriction as a normal $\mathrm{FEV}_{1} / \mathrm{FVC}$ ratio with $\mathrm{FVC}$ less than the lower limit of normal; and mixed obstruction and restriction as having $\mathrm{FEV}_{1}, \mathrm{FVC}$, and $\mathrm{FEV}_{1} / \mathrm{FVC}$ ratio all less than the lower limit of normal. We used the $\mathrm{FEV}_{1}$ percent predicted to categorize such abnormalities as mild, moderate, moderately severe, severe, or very severe [Pellegrino et al. 2005].

\section{Impulse Oscillometry (IOS)}

Many occupational lung diseases (e.g., chronic obstructive pulmonary disease (COPD), asthma) involve the small airways; however, this part of the lung is difficult to evaluate noninvasively. Oscillometry is a helpful technology to understand the effects of occupational exposures on the small airways. There are no contraindications to the test as this test is conducted using regular breathing and does not require a forceful exhalation [Smith et al. 2005]. Spirometry can be normal despite respiratory symptoms or evidence of small airways disease on lung biopsy [King et al. 2011; Oppenheimer et al. 2007]; therefore, oscillometry results complement spirometry and can be used when spirometry is not possible because of a contraindication.

We used an impulse oscillometry machine (CareFusion Corp., San Diego, CA) to measure resistance $(\mathrm{R})$, the energy required to propagate the pressure wave through the airways, and reactance $(\mathrm{X})$, which reflects the viscoelastic properties of the respiratory system. The impulse oscillometry testing machine sends sound waves called pressure oscillations at different frequencies (e.g., 5 Hertz and 20 Hertz) into the airways to measure how airways respond to these small pressures. The test calculates 1) the airway resistance at different frequencies including 5 Hertz (R5) and 20 Hertz (R20), and the difference between R5 and R20 (DR5-R20); 2) the reactance at different frequencies including 5 Hertz (X5); 3) resonance frequency (Fres) which is the frequency where there is no airway reactance; and 4) the total reactance (AX) at all frequencies between 5 Hertz and the Fres. The predicted values for $\mathrm{R}$ and $\mathrm{X}$ were based on sex and age according to reference values recommended by the manufacturer [Vogel and Smidt 1994]. R5 was considered abnormal (elevated) if the measured value was equal to or greater than 140 percent of the predicted R5. X5 was considered abnormal (decreased) if the value of the predicted X5 minus measured X5 was equal to or greater than 0.15 kilopascals per liter per second $(\mathrm{kPa} /(\mathrm{L} / \mathrm{s}))$. DR5-R20 values greater than 30\% were considered abnormal and evidence of frequency dependence [Smith 2015]. We interpreted the test as normal if both the R5 and X5 were normal [Smith 2015]. We defined possible large (central) airways abnormality as a normal X5 and elevated R5 with no evidence of frequency dependence. We defined a possible small airways abnormality if there was evidence of frequency dependence and/or a decreased X5 with or without an elevated R5. We defined possible combined small (peripheral) and large (central airways) abnormality as a decreased X5 and elevated R5 with no evidence of frequency dependence.

Bronchodilator Reversibility Testing for Impulse Oscillometry and Spirometry

If a participant had abnormal impulse oscillometry or spirometry, we repeated both tests after 
the participant received a bronchodilator inhaler medication (i.e., albuterol), which can open the airways in some individuals (e.g., asthmatics). For oscillometry, we defined reversibility (improvement) after bronchodilator administration as a decrease of at least $20 \%$ of either Fres or R5 or a decrease of $40 \%$ for AX. For spirometry, we defined reversibility (improvement) as increases of at least $12 \%$ and $200 \mathrm{~mL}$ for either FEV1 or FVC after bronchodilator administration.

\section{Fractional Exhaled Nitric Oxide (FeNO)}

We used the NIOX MINO ${ }^{\circledR}$ device (Aerocrine Inc., Morrisville, NC) to measure the amount of nitric oxide in the air the participant breathed out. Nitric oxide is a gas that is produced by the airways, and elevated levels can be a sign of eosinophilic airway inflammation in asthma [Dweik et al. 2011]. In adults, fractional nitric oxide concentration in exhaled breath levels above $50 \mathrm{ppb}$ are considered elevated. In adults with asthma, elevated levels may indicate that their asthma is uncontrolled [Dweik et al. 2011].

\section{Statistical Analysis}

Industrial Hygiene Survey and Ventilation Assessment

We performed analyses using Excel (Microsoft ${ }^{\circledR}$, Redmond, WA) and SAS version 9.3 (SAS Institute, Cary, NC). We created summary statistics by work area location, job title, and task. When the values presented in the report are from samples below the LOD they are denoted by a "<" symbol.

\section{Medical Survey}

We calculated frequencies and standardized morbidity ratios (SMRs) and their associated 95\% confidence intervals (CIs) using SAS version 9.3 (Cary, NC). The SMRs compared prevalences of symptoms among participants to expected prevalences of a sample of the general population reflected in the NHANES III (1988-1994) and NHANES 2007-2012, adjusting for sex, race/ethnicity, age (less than 40 years old or 40 years or greater), and cigarette smoking categories (ever/never). For comparisons to the U.S. population, we used the most recent NHANES survey available for the specific comparisons.

\section{Results}

\section{Industrial Hygiene Survey Results}

\section{Personal and Area Full-shift Air Sampling Results}

Personal and area full-shift air sampling results using OSHA Method 1013/1016 can be seen in Table A1. We collected 37 personal and 108 area full-shift air samples over three days. Thirty-one of the 37 personal air samples were above the NIOSH REL for diacetyl of 5 ppb, and five were above the NIOSH REL for 2,3-pentanedione of $9.3 \mathrm{ppb}$. Employees with personal air samples above the NIOSH REL for diacetyl perform various tasks including roasting $(n=9)$, roaster support/working with green beans $(n=1)$, grinding $(n=1)$, packaging $(n=16)$, and maintenance $(n=1)$. Five samples collected on employees with primary duties in the packaging $(n=4)$ and roasting areas $(n=1)$ were above the NIOSH REL for 
2,3-pentanedione. All personal air samples collected on employees with primary duties in the office areas were below the NIOSH REL for diacetyl. All personal samples were below the LOD for 2,3-hexanedione.

Seventy-four of the 108 area full-shift air samples were above the NIOSH REL for diacetyl. Because area air samples are not personal air samples collected directly on an employee, the NIOSH RELs are not directly applicable to the results for exposure monitoring purposes. However, area air samples can highlight areas with higher exposure risk, and the RELs can be used as points of reference. The following areas had one or more 6-hour air level(s) that exceeded the NIOSH REL for diacetyl: the three roasters (range: 7.2 ppb-19.9 ppb), the QC grinder near the roasters $(12.6 \mathrm{ppb}-18.3 \mathrm{ppb})$, the three main grinders (4.4 ppb - 88.7 ppb), all twelve packaging areas sampled $(3.7 \mathrm{ppb}-24.7 \mathrm{ppb})$, the production storage area (3.7 $\mathrm{ppb}-13.6 \mathrm{ppb})$, and the production shipping area $(5.0 \mathrm{ppb}-16.6 \mathrm{ppb})$ (Table A1).

Eighteen of the 108 area full-shift air samples were above the NIOSH REL for 2,3-pentanedione. Because area air samples are not personal air samples collected directly on an employee, the NIOSH RELs are not directly applicable to the results for exposure monitoring purposes. The following areas had one or more 6-hour air level(s) that exceeded the NIOSH REL for 2,3-pentanedione: the G120 roaster (range: $5.5 \mathrm{ppb}-14.3 \mathrm{ppb}$ ), the R1 roaster (range: $7.6 \mathrm{ppb}-12.8 \mathrm{ppb}$ ), the QC grinder near the roasters $(6.8 \mathrm{ppb}-11.2 \mathrm{ppb})$, the three main grinders $(3.8 \mathrm{ppb}-64.1 \mathrm{ppb})$, and five of the 12 packaging areas sampled (3.7 $\mathrm{ppb}-14.6 \mathrm{ppb})$.

Areas near the grinders consistently had the highest level of diacetyl and 2,3-pentanedione. The highest 6-hour area air levels for diacetyl and 2,3-pentanedione were measured at the grinder by the GL14 packaging line (maximum: 88.7 ppb diacetyl and 64.1 ppb 2,3-pentanedione). The second highest 6-hour area air levels for diacetyl and 2,3-pentanedione were measured at the 669 grinder (maximum: $67.6 \mathrm{ppb}$ diacetyl and $32.9 \mathrm{ppb}$ 2,3-pentanedione). The third highest 6-hour area air levels for diacetyl and 2,3-pentanedione were measured at the FRAC grinder (maximum: 42.5 ppb diacetyl and 18.6 ppb 2,3-pentanedione).

\section{Task-Based Air Sampling Results}

Personal task air concentration results can be seen in Tables A2 and A3. We collected 51 personal task air samples using OSHA Method 1013/1016 (Table A2). Task duration ranged from three minutes to 29 minutes. We collected personal task air samples while employees roasted coffee $(n=13)$, ground coffee $(n=1)$, packaged coffee $(n=30)$, performed tasks in the warehouse $(n=3)$, and performed tasks with green beans $(n=4)$. The highest task-based TWA exposures to diacetyl (30.7 ppb) and 2,3-pentanedione (27.0 ppb) were measured while an employee roasted coffee (Table A2). The second highest task-based TWA exposure to diacetyl $(29.7 \mathrm{ppb})$ was observed while an employee packaged coffee. The single $(\mathrm{n}=1)$ taskbased sample using OSHA Method 1013/1016 collected while an employee ground coffee measured $24.0 \mathrm{ppb}$ diacetyl and $14.1 \mathrm{ppb}$ 2,3-pentanedione. The highest exposures to diacetyl and 2,3-pentanedione while employees performed tasks with green beans in the roasting area were $18.1 \mathrm{ppb}$ and $9.1 \mathrm{ppb}$, respectively. Diacetyl and 2,3-pentanedione air concentrations 
measured when an employee performed tasks in the warehouse were $5.5 \mathrm{ppb}$ and $2.4 \mathrm{ppb}$, respectively.

We collected 33 samples that were 15 minutes in duration and could be compared to the NIOSH STELs. One 15-minute sample collected while an employee roasted coffee (30.7 $\mathrm{ppb})$ and one sample collected while an employee packaged coffee $(27.1 \mathrm{ppb})$ were above the NIOSH STEL of $25 \mathrm{ppb}$ for diacetyl. None of the 15-minute samples collected exceeded the NIOSH STEL for 2,3-pentanedione.

We collected 36 personal samples near the breathing zone of employees using instantaneous canisters (Table A3). Levels of diacetyl and 2,3-pentanedione observed in the breathing zone of employees using instantaneous canisters were higher than the levels described above. The highest instantaneous levels were measured for tasks related to grinding. Instantaneous breathing zone samples taken while employees dumped roasted beans into a grinder ranged from $80.1 \mathrm{ppb}$ to $370 \mathrm{ppb}$ diacetyl and $30.4 \mathrm{ppb}$ to $131 \mathrm{ppb}$ 2,3-pentanedione. Instantaneous samples taken at the breathing zone of employees while they ground coffee ranged from $3.9 \mathrm{ppb}$ to $109 \mathrm{ppb}$ for diacetyl, and less than $0.6 \mathrm{ppb}$ to $39.8 \mathrm{ppb}$ for 2,3-pentanedione. Instantaneous samples collected at the breathing zone of an employee when they dumped roasted beans from the roaster into the cooling bin of the roaster ranged from $12.8 \mathrm{ppb}$ to $32.9 \mathrm{ppb}$ for diacetyl and $6.9 \mathrm{ppb}$ to $16.8 \mathrm{ppb}$ for 2,3-pentanedione.

\section{Source Air Sampling Results}

Instantaneous evacuated canister concentrations for diacetyl and 2,3-pentanedione can be seen in Table A4. Instantaneous samples were less than 30 seconds in duration. We collected 23 source samples using evacuated canisters. The highest instantaneous source sample for diacetyl (4505 ppb) and 2,3-pentanedione (1841 ppb) was measured at the FRAC grinder, when the FRAC grinder was dumping organic French roast ground coffee into a hopper. Five of the six instantaneous samples taken near grinders had diacetyl levels greater than $350 \mathrm{ppb}$ and 2,3-pentanedione levels greater than $100 \mathrm{ppb}$. Higher levels of diacetyl (173 ppb) and 2,3-pentanedione (47.3 ppb) were observed at movable hoppers filled with ground coffee as well.

\section{Bulk Samples and Headspace Results}

Headspace results of diacetyl, 2,3-pentanedione, and 2,3-hexanedione for the bulk samples of roasted coffee beans can be seen in Table A5. The highest air concentrations of diacetyl $(10085 \mathrm{ppb})$ and 2,3-pentanedione (9639 ppb) were observed in the headspace of a medium roast coffee sample. The highest air concentration of 2,3-hexanedione ( $264 \mathrm{ppb}$ ) was observed in the headspace of an extra dark French roast sample.

\section{Real-time Monitoring: Carbon Dioxide (CO $\mathrm{C}_{2}$, Carbon Monoxide (CO), and Total Volatile Organic Compounds (TVOCs)}

A summary of the real-time $\mathrm{CO}_{2}, \mathrm{CO}$, temperature, and total VOC monitoring results can be seen in Table A6. Levels of $\mathrm{CO}_{2}$ and $\mathrm{CO}$ measured at the main grinders (669 grinder, the grinder by GL14, and the FRAC Grinder) ranged from $227 \mathrm{ppm}$ to $2103 \mathrm{ppm}$ for $\mathrm{CO}_{2}$ and $<0.1 \mathrm{ppm}$ to $338 \mathrm{ppm}$ for $\mathrm{CO}$. Total VOC measurements at the main grinders ranged from 53 
ppb to $39,164 \mathrm{ppb}$. Levels of $\mathrm{CO}_{2}$ and $\mathrm{CO}$ measured at the QC grinder by the roasters ranged from $379 \mathrm{ppm}$ to $561 \mathrm{ppm}$ for $\mathrm{CO}_{2}$ and $3.2 \mathrm{ppm}$ to $33.1 \mathrm{ppm}$ for CO. Total VOC levels ranged from $2676 \mathrm{ppb}$ to $46,548 \mathrm{ppb}$ at the $\mathrm{QC}$ grinder by the roasters.

Levels of $\mathrm{CO}_{2}$ and $\mathrm{CO}$ at the roasters ranged from $383 \mathrm{ppm}$ to $763 \mathrm{ppm}$ for $\mathrm{CO}_{2}$ and $3.1 \mathrm{ppm}$ to $14.5 \mathrm{ppm}$ for CO. Total VOC measurements at the roasters ranged from $2 \mathrm{ppb}$ to 14,515 ppb. Levels of $\mathrm{CO}_{2}$ and $\mathrm{CO}$ at the packaging lines (can and $\mathrm{G} 14$ packaging line; capsule packaging line; G14C packaging line) ranged from $340 \mathrm{ppm}$ to $1886 \mathrm{ppm}$ for $\mathrm{CO}_{2}$ and $<0.1$ ppm to $22.0 \mathrm{ppm}$ for $\mathrm{CO}$.

A summary of continuous, real-time, personal measurements of $\mathrm{CO}$ can be seen in Table A7. TWA personal $\mathrm{CO}$ measurements ranged from $<0.1 \mathrm{ppm}$ to $12.3 \mathrm{ppm}$ and were below the NIOSH REL of $35 \mathrm{ppm}$ for CO exposure. Two of the three roaster operators had maximum $\mathrm{CO}$ measurements (203 ppm and $267 \mathrm{ppm}$ ) that exceeded the NIOSH ceiling limit of 200 ppm.

\section{Personal Exhaled CO Measurements}

Thirty-five employees that participated in the personal air sampling also provided breath samples for measurement of $\mathrm{CO}$ by exhaling into a monitor at various times during the workday. Measurements were typically collected at the beginning of the shift, lunch break, and at the end of the shift. After the participant exhaled into the monitor, the device reported a $\mathrm{CO}$ value in ppm and also calculated an estimated $\mathrm{COHb}$ percentage. The overall average $\mathrm{CO}$ level was $4.1 \mathrm{ppm}$ (range: 0 ppm-18 ppm), and average $\mathrm{COHb}$ was $1.2 \%(0 \%-3.5 \%)$. Average $\mathrm{CO}$ level in smokers was $7.7 \mathrm{ppm}$ (range: $0 \mathrm{ppm}-18 \mathrm{ppm}$ ), and average $\mathrm{COHb}$ was $1.8 \%$ (range: $0 \%-3.5 \%$ ). All $\mathrm{COHb}$ test results in non-smokers were below $1.6 \%$ and in smokers were below $3.5 \%$.

\section{Ventilation Assessment}

The size of the mechanical ventilation systems and their layout precluded us from taking a detailed set of airflow measurements. Given that most of the systems had no ductwork and only one or two supply or return openings, the airflow rates through those openings were too high for the equipment we had available. The two units in the green bean storage area did have flexible duct socks installed to help more evenly distribute the air, but obtaining accurate airflow measurements through the duct socks would have been impractical. Therefore, we physically inspected the ventilation equipment and recorded pertinent information from each system, when available.

The ventilation in the roasting and packaging area of the facility consisted of three Reznor (Reznor LLC, Mercer, PA) Model RGBL 600 make-up air units (MUA-6, MUA-7, and MUA-8). Depending on the setup of each unit, each one is capable of supplying between 4500 and 12,500 cubic feet per minute of outdoor air to the production space. There was no extensive supply ductwork system associated with any of the MUA units; the supply air was pushed into the space directly below the roof mounted MUA units. The roasting and packaging space was also served by two evaporative coolers (ECs). EC-7 was a Champion Cooler/Essick Air (Essick Air Products, Inc. and Champion Cooler Corporation, Little Rock, 
AR) Model 16000D evaporative cooler, while EC-8 was a Phoenix (Phoenix Manufacturing, Inc., Phoenix, AZ) Model D2231 A evaporative cooler. The airflow rates through either EC are dependent on the blower motor power and speed settings, but both ECs are capable of moving 10,000 cubic feet per minute or more.

The adjacent green bean storage area had two roof-mounted ventilation components as well; one MUA unit and one EC. MUA-5 is roof-mounted near the southern end, and nearly centered east to west, of the green bean storage area. MUA-5 was a Reznor Model RGBL 600 make-up air unit, like the three in the roasting and packaging space. EC-6 was a Phoenix Model D2231A evaporative cooler roof-mounted closer to the northern end, and nearly centered east to west, in the green bean storage area. Both units in the green bean storage area were equipped with fabric duct socks running east to west through the area. During our visit, MUA-5 was not used, but EC-6 did provide supply air to the green bean storage facility.

In addition to the roof-mounted ventilation systems, the facility had three large exhaust fans installed through the wall to exhaust air to the outdoors. Two of the wall fans were installed along the east wall of the roasting and packaging area, one near the maintenance area, and one in the production storage area. The third wall fan was high on the southern wall of the green bean storage area. During our visit, the two fans in the roasting and packaging area were operating, but we did not see the exhaust fan in the green bean storage area powered on.

\section{Medical Survey Results November-December 2016}

Demographics

Forty of 46 onsite employees ( $87 \%$ ) on the roasting and production sub teams participated in the medical survey. The majority of participants were male $(65 \%)$ and Spanish, Hispanic or Latino (53\%), with a mean age of 39 years and average tenure at the company of five years. Seven (18\%) participants worked at another coffee roasting and packaging facility or in coffee cafés prior to working at this facility. Sixteen (40\%) participants were current or former smokers.

All 40 medical survey participants reported working in or entering the production area for an average of 38 hours per week, ranging from one to 40 hours a week. Thirty-nine (98\%) of 40 participants reported being within an arm's length of roasted coffee in one or more areas of the production process. Thirty-nine (98\%) of 40 participants worked full-time in the production area processing coffee.

\section{Symptoms and Self-Reported Diagnoses}

The prevalence of symptoms over the last year and last four weeks at the time of the survey are listed in Table A8. Nose symptoms were the most commonly reported symptom ( $\mathrm{n}=19$, $48 \%)$, followed by eye symptoms ( $\mathrm{n}=14,35 \%)$. Ten $(42 \%)$ of 24 participants who reported nose and/or eye symptoms reported these symptoms were better away from work or aggravated by work. Some production employees noted that their nose or eye symptoms were caused or aggravated by green coffee bean dust, chaff, ground coffee, or smoke.

Cough $(n=7,18 \%)$ and wheeze $(n=7,18 \%)$ were the most commonly reported lower 
respiratory symptom. Four (31\%) of 13 participants who reported cough and/or wheeze reported these symptoms were better away from work or aggravated by work. Shortness of breath on level ground or walking up a slight hill was reported by five (13\%) participants; none of these participants reported that their shortness of breath began after they started employment at the facility. Breathing trouble and chest tightness were each reported by four $(10 \%)$ participants; three of these participants reported their breathing trouble or chest tightness was better away from work or aggravated by work. Flu-like achiness or achy joints was the most commonly reported systemic symptom $(n=12,30 \%)$. Three $(18 \%)$ of 17 participants who reported systemic symptoms reported that their systemic symptoms were better when away from work or aggravated by work.

Six participants reported a diagnosis of hay fever or nasal allergies; one participant was diagnosed with hay fever or nasal allergies after beginning employment at this coffee roasting and packaging facility. Six participants reported ever being diagnosed with asthma, and four reported a current diagnosis with asthma; all participants reporting asthma were diagnosed prior to employment at the coffee roasting and packaging facility. No participants reported a diagnosis of chronic bronchitis, emphysema, COPD, bronchiolitis obliterans, interstitial lung disease, hypersensitivity pneumonitis, chemical pneumonitis, sarcoidosis, heart disease, or vocal cord dysfunction.

\section{Medical Tests}

Thirty-eight of 40 medical survey participants performed two or more medical tests. Thirtyseven participants performed spirometry and none had abnormal test results. Sixteen (42\%) of 38 participants who performed IOS had test results interpreted as abnormal: seven consistent with small airway abnormality, five consistent with large airway abnormality, and four consistent with small and large airway abnormalities. Seven (44\%) of these 16 participants had significant improvement in IOS after taking a bronchodilator. Four $(11 \%)$ of 37 participants that performed exhaled nitric oxide tests had tests interpreted as elevated. Of the 19 participants with abnormal IOS or elevated exhaled nitric oxide, two (11\%) reported one or more lower respiratory symptoms improved away from work. Two additional participants with normal medical test results reported one or more of their lower respiratory symptoms were caused or aggravated by work.

\section{NHANES Comparison of Symptoms and Diagnoses}

The SMR for ever receiving a physician diagnosis of asthma was elevated at 2.4, although as previously noted all cases were initially diagnosed before working in the facility (Table A9). Prevalences of shortness of breath, wheeze, cough, phlegm, sinus problems, and nose and eye symptoms were not elevated in comparison to the general U.S. population, adjusted for age distribution, race/ethnicity, sex, and smoking history.

\section{Discussion}

Diacetyl, 2,3-pentanedione, 2,3-hexanedione, other VOCs, and other compounds such as $\mathrm{CO}_{2}$ and $\mathrm{CO}$ are naturally produced when coffee beans are roasted, and grinding the roasted 
coffee beans produces greater surface area for the off-gassing of these chemicals [Anderson et al. 2003; Akiyama et al. 2003; Daglia et al. 2007; Newton 2002; Nishimura et al. 2003; Raffel and Thompson 2013]. Overall, the highest area samples for total VOCs, CO, diacetyl, and 2,3-pentanedione were observed in areas where coffee was ground (near the 669 grinder, the grinder by GL14, and the FRAC grinder). We also observed elevated levels of diacetyl and 2,3-pentanedione near movable hoppers that stored ground coffee, and that were located in multiple locations throughout the facility. The storage of ground coffee in movable hoppers throughout the facility may have contributed to diacetyl and 2,3-pentanedione levels measured in the packaging and roasting areas as well. Additionally, large accessory fans that were used in multiple areas of the facility may have helped circulate air from areas near sources and higher concentrations of diacetyl and 2,3-pentanedione into areas of lower concentrations of diacetyl and 2,3-pentanedione.

\section{Alpha-Diketones}

Personal Air Sampling

Thirty-one personal full-shift air samples (collected on employees with roasting, packaging, grinding, maintenance, and green bean storage duties) taken inside the facility using standard OSHA methods were above the NIOSH REL for diacetyl. The highest personal full-shift air samples (19.7 ppb and $24.5 \mathrm{ppb})$ were collected on employees with roasting and packaging duties. Four personal air samples collected on employees with packaging duties and one personal air sample collected on a roaster operator were above the NIOSH REL for 2,3-pentanedione. As noted earlier, the REL should be used as a guideline to indicate when steps should be taken to reduce exposures in the workplace. The risks associated with the measured levels are higher than NIOSH recommends. As described in the quantitative risk assessment from the NIOSH Criteria Document (Table 5-27) [NIOSH 2016], after a 45year working lifetime exposure to $20 \mathrm{ppb}$ (a concentration slightly lower than the highest concentration measured at this facility), NIOSH estimated that 3 in 1,000 workers would develop reduced lung function (FEV1 below the 5th percentile). NIOSH predicted that around 5 in 10,000 workers exposed to diacetyl at $20 \mathrm{ppb}$ would develop more severe lung function reduction (FEV1 below $60 \%$ predicted, defined as at least moderately severe by the American Thoracic Society [Pellegrino et al. 2005]). After a 45-year working lifetime exposure to $50 \mathrm{ppb}$ (a concentration higher than the highest concentration measured at this facility), NIOSH estimated that 8 in 1,000 workers would develop reduced lung function (FEV1 below the 5th percentile). NIOSH predicted that 12 in 10,000 workers exposed to diacetyl at $50 \mathrm{ppb}$ would develop more severe lung function reduction. The effects of a working lifetime exposure at $25 \mathrm{ppb}$ would be between those for $20 \mathrm{ppb}$ and $50 \mathrm{ppb}$. NIOSH recommends keeping diacetyl concentrations below 5 ppb because at this level, the risk of reduced lung function after a working lifetime of exposure is below 1 in 1000 workers. $\mathrm{NIOSH}$ recommends taking steps to reduce diacetyl exposures to below the REL of $5 \mathrm{ppb}$ whenever possible.

\section{Area Air Sampling}

Areas near the roasters, grinders, QC grinder by the roasters, all packaging lines, production shipping area, and the production storage area had air levels that exceeded the NIOSH REL for diacetyl. Areas near the roasters, main grinders, and packaging lines also had air levels 
that exceeded the NIOSH REL for 2,3-pentanedione. Of the 108 full-shift area samples, 74 were above the NIOSH REL for diacetyl and 18 were above the NIOSH REL for 2,3-pentanedione. Areas where coffee was ground (near 669 grinder, the grinder by GL14, and the FRAC grinder) consistently had the highest diacetyl (maximums: 42.5-88.7 ppb) and 2,3-pentanedione (maximums: 18.6-64.1 ppb) air levels. We note that NIOSH RELs are intended to be directly compared to personal measurements; therefore, an area air sample that exceeds a NIOSH REL is only an indication of potential personal exposures.

\section{Task-Based Exposures}

Coffee processing involves multiple tasks that may cause intermittent exposure to diacetyl and 2,3-pentanedione. Traditional full-shift sampling will not characterize these intermittent, peak exposures. Evaluating intermittent and task-based exposures to diacetyl and 2,3-pentanedione is difficult with current validated sampling methods (OSHA Methods 1013/1016). Since tasks are so sporadic in coffee processing, with some only lasting a few seconds or minutes, we used instantaneous evacuated canisters to sample tasks that were only a few seconds to minutes long and OSHA Methods 1013/1016 for longer duration tasks. We sampled by task, with varying durations, to understand which tasks may have contributed to higher exposures to diacetyl and 2,3-pentanedione.

Our task-based air sampling revealed that some tasks had higher air concentrations of diacetyl and/or 2,3-pentanedione than other tasks. The highest TWA exposures to diacetyl (30.7 ppb) and 2,3-pentanedione (27.0 ppb) were measured while an employee roasted coffee (Table A2). We also measured higher exposures to diacetyl (27.1 ppb) and 2,3-pentanedieone (11.9 ppb) during packaging coffee. One 15-minute sample collected while an employee roasted coffee and one sample collected while an employee packaged coffee were above the NIOSH STEL for diacetyl.

We also measured diacetyl and 2,3-pentanedione using instantaneous sampling, in which sample duration was less than 30 seconds. These instantaneous samples were collected to identify and describe short-duration tasks and point sources of diacetyl and 2,3-pentanedione. The highest instantaneous levels taken at the breathing zone of employees were measured while employees performed tasks associated with grinding. Instantaneous samples taken at the breathing zone of employees while they ground coffee were as high as $109 \mathrm{ppb}$ for diacetyl, and $39.8 \mathrm{ppb}$ for 2,3-pentanedione. Breathing zone samples taken while employees dumped roasted beans into a grinder ranged from $80.1 \mathrm{ppb}$ to $370 \mathrm{ppb}$ diacetyl and $30.4 \mathrm{ppb}$ to $131 \mathrm{ppb} 2,3$-pentanedione. The greater surface area for off-gassing that is produced during grinding could have resulted in the higher air concentrations [Akiyama et al. 2003].

\section{Source Air Sampling}

The highest instantaneous source sample for diacetyl (4505 ppb) and 2,3-pentanedione (1841 ppb) was measured at the FRAC grinder, when the FRAC grinder was dumping freshly ground coffee into a hopper. Five of the six instantaneous samples taken near grinders had diacetyl levels greater than $350 \mathrm{ppb}$ and 2,3-pentanedione levels greater than $100 \mathrm{ppb}$. As mentioned above, grinding creates a greater surface area for off-gassing from roasted coffee beans, which may have resulted in the higher air concentrations observed during grinding 
[Akiyama et al. 2003]. Elevated levels of diacetyl (173 ppb) and 2,3-pentanedione (47.3 ppb) were also observed at movable hoppers filled with ground coffee.

\section{Bulk samples}

Diacetyl is not found in green coffee beans. Rather, diacetyl is generated later in the coffee roasting process [Daglia et al. 2007]. As expected, we found that roasted coffee emits alphadiketones into the headspace of sealed vessels, indicating that roasted coffee is a source of alpha-diketones in the facility. The amount of time beans were roasted, and the amount of time roasted beans off-gassed prior to the collection of bulk samples could be responsible for differences in headspace analysis results.

\section{Real-time Sampling for $\mathrm{CO}, \mathrm{CO}_{2}$ and VOCs}

Our real-time monitoring found that the highest overall levels of total $\mathrm{CO}, \mathrm{CO}_{2}$, and $\mathrm{VOCs}$ were observed at the main grinders. None of the average area or personal levels of $\mathrm{CO}$ exceeded the NIOSH REL (35 ppm) or OSHA PEL (50 ppm). However, two personal samples collected on roaster operators exceeded the NIOSH ceiling (200 ppm) for CO. Additionally, levels of $\mathrm{CO}$ measured near the FRAC grinder also exceeded the NIOSH ceiling limit for $\mathrm{CO}$. The NIOSH ceiling limit should not be exceeded at any time. The average $\mathrm{CO}_{2}$ concentrations observed at the grinders were 432 ppm (669 grinder), 573 ppm (the grinder by GL14), and $502 \mathrm{ppm}$ (FRAC grinder) with a maximum of $2103 \mathrm{ppm}$. All $\mathrm{CO}_{2}$ measurements were below the NIOSH REL (5,000 ppm) and OSHA PEL (5,000 ppm).

\section{Ventilation}

As shown in Table A1, concentrations of alpha-diketones were elevated throughout the roasting, packaging, and grinding areas, including the production storage and production shipping areas. Alpha-diketone concentrations were generally low in all other areas of the plant. Seasonal changes impacting the operational state of various exhaust fans, evaporative coolers and make-up air units throughout the facility could cause fluctuations in airborne concentrations of diacetyl and 2,3-pentanedione as well.

\section{Local exhaust ventilation}

Local exhaust ventilation systems can capture contaminants when generated and remove contaminants before inhalation by employees can occur. Local exhaust ventilation systems generally consist of hoods or enclosures, duct work, or fans. Depending on the contaminant and whether air is recirculated, filters or other air cleaning technologies can also be incorporated. After properly designed local exhaust ventilation systems are installed, overall workplace exposure levels can be reduced by removing contaminants at the source. Higher concentrations of alpha-diketones were measured at the three main grinders, near the roasters, and near all packaging lines. The overall layout of the facility, including the coffee transfer lines from various grinders to packaging lines and the close proximity of various operations to each other, presents some unique challenges to incorporating effective local exhaust ventilation. The three main grinders and various point-sources on coffee packaging lines could be modified with local exhaust ventilation that would help reduce overall alphadiketone concentrations in the facility. Additional sampling can be done to further identify point sources of alpha-diketone emissions associated with each process. Once point sources 
are identified, local exhaust ventilation can be used to reduce employee exposures.

\section{General exhaust or dilution ventilation}

An adequate supply of outdoor air, typically delivered through the heating, ventilation, and air-conditioning system, is necessary in any occupied spaces to dilute pollutants that are released by equipment, processes, products, and people. In an ideal environment, good general ventilation provides fresh air into the space and removes contaminated air. This is generally done by providing fresh outdoor air (or recirculated, filtered air) to the space to provide dilution. Simultaneously, air is exhausted from the space to remove the contaminants. A limitation of general exhaust ventilation is that unlike local exhaust ventilation, general exhaust ventilation does not capture contaminants at or near the source where employees may be performing job duties. Rather, general exhaust ventilation can serve to dilute the concentration of the contaminant in a production space to acceptable levels but may not be protective for employees working in close proximity to a point source of a contaminant.

During our visit, three make-up air units and two evaporative coolers, all capable of supplying fresh air to the roasting and packaging area, were present. The systems were reported to operate intermittently and seasonally. Air was being exhausted from the space via the roasters and large wall-mounted exhaust fans. We were unable to accurately measure the amount of fresh, outdoor air being provided by the various rooftop MAU units and ECs to the roasting and packaging space. The outdoor air supply may be sufficient. However, if the amount of outdoor air supplied to the space is low, then increasing the outdoor airflow will provide more dilution and removal of airborne contaminants from the space. All of the existing ventilation equipment can be easily modified to move more air if necessary. Providing more outdoor airflow may enhance dilution and removal of contaminants; however, there will be additional energy costs associated with heating and cooling the outside air introduced into the facility for much of the year. Additionally, increased outdoor airflow into the facility may not bring all diacetyl and 2,3-pentanedione levels below the NIOSH RELs. Decisions about ventilation should be made as part of an overall plan to improve engineering controls at the facility. A ventilation system expert can help meet all ventilation requirements in the production space and other areas of the building occupied by employees.

\section{Relocation or enclosure of specific processes}

Engineering controls may help mitigate exposures in the roasting and packaging area. In some cases, consideration should be given to relocating processes or specific pieces of equipment to simplify the implementation of engineering controls. For example, relocating the three large grinders to more isolated areas of the plant, particularly near an exterior wall, would simplify the implementation of local exhaust ventilation at the grinders. The grinders could then be isolated in their own room, which could be ventilated separately from the larger space. Having a separate room with separate ventilation for storing full containers of whole-bean or ground coffee may also further reduce concentrations of alpha-diketones in the overall roasting and packaging area.

Additional air sampling should be conducted if there are changes in production processes, controls, or work practices that potentially change exposure conditions within the workplace. 


\section{Medical Survey}

Overall, mucous membrane symptoms, specifically nose and eye symptoms, were the most commonly reported symptoms. Some production employees reported their mucous membrane symptoms were caused or aggravated by green coffee dust, chaff, ground coffee, or smoke. Coffee dust is an organic dust and, as noted earlier, exposure to coffee dust is known to cause respiratory symptoms and is a known risk factor for occupational asthma [Karr et al. 1978; Zuskin et al. 1979, 1985, 1993; Thomas et al. 1991; Sakwari et al. 2013].

Upper respiratory disease such as allergic rhinitis (hay fever, nasal allergies) and sinusitis are sometimes associated with lower respiratory symptoms and asthma and may precede the diagnosis of asthma [Shaaban et al. 2008; EAACI Task Force on Occupational Rhinitis et al. 2008; Rondón et al. 2012, 2017; Sahay et al. 2016]. Upper respiratory involvement (e.g., rhinitis, sinusitis) can result in suboptimal control of asthma. Most (12 of 14; 86\%) participants that reported lower respiratory symptoms also reported nasal or sinus problems or physician-diagnosed hay fever or nasal allergies. Green coffee dust is thought to be a more potent allergen than roasted coffee dust because roasting destroys some of the allergenic activity [Lehrer et al. 1978]. As discussed in the recommendation section, to prevent symptoms related to green coffee dust and chaff, make N95 disposable filtering-face piece respirators available for voluntary use when emptying burlap bags of green beans into the storage silos or when emptying the chaff containers or cleaning the green bean storage area.

The number of participants ever diagnosed with asthma by a physician $(n=6 ; 15 \%)$ was significantly higher than expected compared with the U.S. population with a SMR of 2.4; however, all of these participants were diagnosed before beginning work at this coffee roasting and packaging facility. Of the 14 participants who reported lower respiratory symptom (including participants with asthma), seven (50\%) perceived their lower respiratory symptoms were work-related and five (36\%) developed lower respiratory symptoms after they began working at this facility. Most (9 of 14; 64\%) were also current or former smokers. None of the five who reported developing lower respiratory symptoms after beginning to work at this facility, also reported physician-diagnosed asthma. Asthma symptoms often improve when away from exposures that trigger symptoms while symptoms of other lung diseases such as obliterative bronchiolitis or COPD generally do not improve.

Spirometry can be used to help detect and follow individuals with asthma and other lung diseases such as obliterative bronchiolitis or COPD. Spirometry can show if air is exhaled from the lungs more slowly than normal (i.e. obstructive abnormality) or if the amount of air exhaled is smaller than normal (i.e., restrictive abnormality). In asthma, there is intermittent airways obstruction which is reversible after treatment with bronchodilator medications (e.g., albuterol). In obliterative bronchiolitis, scar tissue prevents the small airways (bronchioles) from opening up when albuterol is given. In other words, the airways are fixed and not responsive (reversible) to bronchodilator medicine. The obstructed airways prevent rapid emptying of the lung air sacs (alveoli) during exhalation. This explains why the respiratory symptoms of those with occupational obliterative bronchiolitis do not tend to improve when away from work-related exposures; however, avoidance of further exposure can stop progression of the disease [Akpinar-Elci et al 2004]. 
Spirometry and impulse oscillometry measure different things. Spirometry assesses airflow and is the breathing test typically used to screen for flavoring-related lung disease. Impulse oscillometry assesses the airways response to a sound or pressure wave and has not commonly been used to screen for flavoring-related lung disease. In general, during the impulse oscillometry test, a small pressure impulse (sound wave) is imposed upon the inspiratory and expiratory airflow during normal tidal breathing. This pressure wave causes a disturbance in the airflow and pressure, and the response of the airways (i.e., change in pressure to change in flow) is a measure of the resistance to airflow in the airways [Desiraju and Agrawal 2016]. Impulse oscillometry may be useful as an indirect measure of airflow obstruction and helpful in individuals not able to perform forced breathing maneuvers that are required during the spirometry test. The impulse oscillometry test has been used for many years to measure changes in the airways of children with lung problems such as asthma and cystic fibrosis [Song et al. 2008; Komarow et al. 2011; Shi et al. 2012; Schulze et al. 2016]. More recently, impulse oscillometry has been used to investigate lung problems in adults exposed to dust or chemicals, such as World Trade Center emergency responders and soldiers returning from deployment overseas [Oppenheimer et al. 2007; Berger et al. 2013; Weinstein et al. 2016]. Over the years, researchers have developed reference (predictive) equations for different populations of children for oscillometry [Malmberg et al. 2002; Park et al. 2011; Lee et al. 2012; de Assumpção et al. 2016]. For adults, there are fewer reference equations available for oscillometry [Vogel and Smidt 1994; Newbury et al. 2008; Schulz et al. 2013]. The predicted values we used for oscillometry measures were based on gender and age according to references values recommended by the manufacturer. Unlike predictive equations used for spirometry, the impulse oscillometry reference equations we used did not take into account height, race, or smoking status [Vogel and Smidt 1994].

Our findings of upper and lower respiratory symptoms that improved away from work or were reported to be caused or aggravated at work in 15 of 40 medical survey participants, and abnormalities on lung function testing in 16 of 38 participants tested with IOS suggest a burden of respiratory problems in this workforce. The upper and lower respiratory symptoms that improve away from work are likely related to workplace exposures. The lung function abnormalities we found are not specific to a particular respiratory problem or disease. They could be related to workplace exposures or to other factors. Indeed, some employees had respiratory diagnoses that preceded employment at this facility, but other participants reported developing lower respiratory symptoms since beginning to work at this facility. Because of the need to protect individuals' privacy, we cannot provide more detailed results that might shed light on possible work-relatedness, such as health measures by job title or task. We mailed each participant their individual lung function test results with an explanation of the results and recommended each participant provide the information to their personal physician.

We recommend starting a medical monitoring program because air sampling detected employee exposures to diacetyl and 2,3-pentanedione that exceeded the NIOSH RELs, and there were a number of participants with abnormal breathing tests or history of lower respiratory symptoms. All production employees and any employees that assist with production tasks (e.g., roasting, interacting with open storage bins/containers of roasted 
coffee, grinding, weighing, or packaging coffee) should participate in the workplace medical monitoring program. A medical monitoring program is a means of early identification of employees who may be developing lung disease (e.g., asthma, obliterative bronchiolitis) and can help prioritize interventions to prevent occupational lung disease. The NIOSH medical survey results can serve as a baseline for employees who participated, if they choose to share these results with the provider. In a workplace with risk of occupational lung disease, prevention of smoking-related lung disease is important and makes the detection of workrelated adverse effects easier. The Centers for Disease Control and Prevention offers tools and resources for setting up a smoking cessation program [CDC 2017b].

\section{Conclusions}

We identified specific work tasks that resulted in air concentrations of diacetyl and 2,3-pentanedione that exceeded the NIOSH RELs for diacetyl and 2,3-pentanedione. Higher full-shift and task-based diacetyl and 2,3-pentanedione exposure measurements were observed on employees that roasted coffee, ground coffee, packaged coffee, performed maintenance tasks, and performed tasks in the green bean storage area. We observed higher instantaneous levels of diacetyl and 2,3-pentanedione during grinding tasks. Areas with ground coffee present, specifically the main grinders, to include the 669 grinder, grinder 1 by GL14, and the FRAC grinder, had the highest levels of diacetyl, 2,3-pentanedione, 2,3-hexanedione, and $\mathrm{CO} . \mathrm{CO}_{2}$ levels were low throughout most of the facility. However, $\mathrm{CO}$ levels measured on roaster operators as well as near the FRAC grinder exceeded the NIOSH ceiling limit of $200 \mathrm{ppm}$.

Consultation with a ventilation engineer to install local exhaust ventilation systems at point sources near the sources and processes with the highest measurements of exposure could mitigate potential exposures to alpha-diketones and CO. A local exhaust ventilation system installed at the grinders to immediately remove alpha-diketones produced during grinder operation could mitigate overall concentrations of alpha diketones and $\mathrm{CO}$. Consideration should be given to relocating processes or specific pieces of equipment to simplify the implementation of engineering controls. Relocating the three large grinders to more isolated areas of the plant, particularly near an exterior wall, would simplify the implementation of local exhaust ventilation at the grinders and could ensure that the grinders are ventilated separately from the larger space. Additionally, a separate room with separate ventilation for storing full containers of whole-bean or ground coffee may also further reduce concentrations of alpha-diketones in the overall roasting and packaging area.

Fresh, outdoor air was supplied to the roasting and packaging area, along with the green bean storage area, by rooftop make-up air units and evaporative coolers. We were unable to measure the amount of fresh, outdoor air supplied to the space during our visit, and that amount varies seasonally and with various combinations of the equipment being operated. The outdoor air supply may be sufficient. However, if the amount of outdoor air supplied to the space is low, then increasing the outdoor airflow will provide more dilution and removal of airborne contaminants from the space. Consistently supplying the production space 
with appropriate outdoor air may not reduce diacetyl and 2,3-pentanedoine concentrations to levels below the NIOSH REL for diacetyl and 2,3-pentanedione. Consultation with a ventilation engineer to optimize outdoor air delivery into the facility may be an easy first step toward engineering control improvements.

Overall, mucous membrane symptoms, specifically eye and nose symptoms, were the most commonly reported symptoms. Some production employees reported their mucous membrane symptoms were caused or aggravated by green coffee dust, chaff, ground coffee, or smoke. Coughing and wheezing or whistling in the chest were the most commonly reported lower respiratory symptoms. Participants reported ever being diagnosed with asthma significantly more than expected compared with the U.S. noninstitutionalized population of the same age, race/ethnicity, sex, and cigarette smoking distribution. Although spirometry was normal in all medical survey participants, 19 (50\%) of 38 medical survey participants had abnormalities on other medical tests. We recommend a medical monitoring program to identify any employees who may be developing lung disease (e.g., asthma, obliterative bronchiolitis) and to help management prioritize interventions to prevent occupational lung disease. All production workers and employees that assist with production tasks (e.g., roasting, interacting with open storage bins/containers of roasted coffee, grinding, weighing, or packaging coffee) should participate in the workplace medical monitoring program.

\section{Recommendations}

On the basis of our findings, we recommend the actions listed below. We encourage this coffee roasting and packaging facility to use a labor-management health and safety committee or working group to discuss our recommendations and develop an action plan. Our recommendations are based on an approach known as the hierarchy of controls. This approach groups actions by their likely effectiveness in reducing or removing hazards. In most cases, the preferred approach is to eliminate hazardous materials or processes and install engineering controls to reduce exposure or shield employees.

\section{Engineering Controls}

Engineering controls reduce employees' exposures by removing the hazard from the process or by placing a barrier between the hazard and the employee. Engineering controls protect employees effectively without placing primary responsibility of implementation on the employee.

1. Consult with a ventilation engineer to install local exhaust ventilation at all grinders, to include the 669 grinder, the grinder by the GL14 packaging line, and the FRAC grinder. Consider moving the grinders to a more isolated area of the facility to make the implementation of effective engineering controls easier.

2. If possible, consider relocating the grinders to an area with little or no bystander foot traffic so as to minimize potential exposure risks to employees not directly using the grinders.

3. Consult with a ventilation engineer to determine if additional fresh, outdoor air can 
be supplied to the roasting and packaging area of the plant. Work with the ventilation engineer to ensure that the production area is maintained under negative pressure relative to non-production spaces.

a. Ensure that all doors between the production and non-production areas are kept closed at all times. An increase in air supplied to the space will need to be offset with an increase in air exhausted from the space as well. Care should be taken to maintain correct pressure relationships between the roasting and packaging area and adjacent spaces. Otherwise, contaminants could be pushed from the roasting and packaging area into adjacent areas and increase worker exposures in non-production locations.

5. Automate transfer of roasted beans or ground coffee, whenever possible, to minimize manual handling.

6. Consider increasing the airflow of the roasters' downdraft tables and/or installing additional local exhaust ventilation at the roasters if alpha-diketone and carbon monoxide concentrations remain elevated after other controls have been implemented.

7. Consider installing local exhaust ventilation at the packaging machines where ground coffee is packaged if alpha-diketone and carbon monoxide concentrations remain elevated after other controls have been implemented.

8. Ensure that accessory fans in use do not blow air from sources such as the roasters, grinders, or hoppers with whole bean or ground coffee, into the breathing zone of employees.

\section{Administrative Controls}

Administrative controls are employer-dictated work practices and policies implemented to reduce or prevent hazardous exposures. Their effectiveness depends on employer commitment and employee acceptance. Regular monitoring and reinforcement are necessary to ensure that policies and procedures are followed consistently.

1. Install a $\mathrm{CO}$ monitor and alarm near the main roasters, the quality control grinders near the roasters, and the three main grinders that can alert employees if and when $\mathrm{CO}$ levels exceed the NIOSH ceiling of $200 \mathrm{ppm}$. Employees should evacuate and move to an area of fresh air until the CO level drops below $200 \mathrm{ppm}$.

2. After engineering controls have been installed at the main grinders, conduct personal air monitoring for diacetyl and 2,3-pentanedione on employees with primary duties in the production area using the modified OSHA sampling and analytical Methods 1013/1016 [OSHA 2008; OSHA 2010; LeBouf and Simmons 2017]. Because air levels of VOCs like diacetyl and 2,3-pentanedione may fluctuate from day to day based on production schedules, we recommend personal air sampling for diacetyl and 2,3-pentanedione over multiple days.

3. Whenever possible, employees should avoid spending time in the immediate area where coffee is being ground and/or ground coffee is being packaged. 
4. Limit the amount of time non-production employees spend in the production area to the extent possible.

5. Whenever possible, cover bins of roasted whole beans and ground coffee to aid in reducing the overall emission of alpha-diketones and other chemicals including $\mathrm{CO}$ and $\mathrm{CO}_{2}$, into the workplace. Specifically, ensure that whenever possible, hoppers filled with ground coffee are kept covered.

6. To reduce exposures to VOCs (including alpha-diketones) and CO, minimize production tasks that require employees to place their heads directly above or inside the roasted bean bins.

7. Continue to periodically clean the roaster's exhaust according to manufacturer instructions to remove chaff build up to reduce a fire hazard and to improve the efficiency, energy usage, and roaster performance.

8. Ensure employees understand potential hazards (e.g., diacetyl, 2,3-pentanedione, $\mathrm{CO}, \mathrm{CO}_{2}$ dust) in the workplace and how to protect themselves. OSHA's Hazard Communication Standard, also known as the "Right to Know Law" [29 CFR 1910.1200] requires that employees are informed and trained on potential work hazards and associated safe practices, procedures, and protective measures.

9. Ensure employees are educated to consider the risks of further exposure if they develop lower respiratory symptoms (e.g., cough, shortness of breath, wheezing) that are progressive and severe in degree. Employees should report new, persistent, or worsening symptoms to their personal healthcare providers and to a designated individual at this workplace. Employees with new, persistent, or worsening symptoms should share this report with their healthcare providers.

\section{Personal Protective Equipment}

We commend the company's efforts prior to our survey in November 2016, to mitigate exposure to diacetyl and 2,3-pentanedione by requiring roaster operators to wear air purifying half-face respirators fitted with organic vapor cartridges. We note that personal protective equipment in the form of respiratory protection is considered the least effective means for controlling hazardous respiratory exposures because breakdowns in implementation can result in insufficient protection. Additionally, some employees mentioned that they experienced discomfort and difficulties in wearing the air-purifying half-face respirators while performing their job duties at the roaster. Proper use of respiratory protection (respirators) requires a comprehensive respiratory protection program and a high level of employee and management involvement and commitment to assure that the right type of respirator is chosen for each hazard, respirators fit users and are maintained in good working order, and respirators are worn when they are needed. Supporting programs such as training, change-out schedules, and medical assessment might be necessary. Respirators should not be the sole method for controlling hazardous inhalation exposures. Rather, respirators should be used until effective engineering and administrative controls are in place.

1. In addition to engineering and administrative controls, respiratory protection is a 
potential option to further reduce exposures to alpha-diketones (e.g., diacetyl and 2,3-pentanedione). If follow-up air sampling after engineering controls have been installed indicates levels of diacetyl and 2,3-pentanedione above their respective NIOSH RELs and STELs, we recommend that respiratory protection be used during tasks with elevated exposures. If respiratory protection is used, NIOSH-certified respirators should be fitted with organic vapor cartridges to protect against diacetyl and 2,3-pentanedione, and particulate filters to protect against dust particles. The choice of respirator should be guided by personal exposure sampling for diacetyl and 2,3-pentanedione (NIOSH 2004). Respirators have assigned protection factors (APFs). APF refers to the highest level of protection a properly selected respirator can provide. For instance, air-purifying half-face respirators have an assigned protection factor (APF) of 10, and air-purifying full-face respirators have an APF of 50. Also, there are powered-air purifying respirators that may be more comfortable for employees than the air-purifying respirators currently in use. The powered-air purifying respirators have APFs of 25, 50, or 1000. The OSHA APFs can be found in Table 1 of OSHA Respiratory Protection Standard at https:/www.osha.gov/pls/oshaweb/owadisp.show document? $\mathrm{p}$ table=STANDARDS\& $\mathrm{p} \mathrm{id}=12716$.

If mandatory respiratory protection is used, a written respiratory protection program should be implemented as required by the OSHA Respiratory Protection Standard (29 CFR 1910.134), including training, fit testing, maintenance and use requirements.

2. Make N95 disposable filtering-face piece respirators available for voluntary use for protection against green or roasted coffee dust exposure such as when emptying burlap bags of green beans into the storage silos, cleaning the roaster exhaust system of chaff, emptying the chaff containers, or cleaning the green bean storage area. N95 respirators should be available in various sizes, and each potential N95 user should receive a copy of Appendix D of the OSHA Respiratory Protection Standard (http://www.osha.gov/ pls/oshaweb/owadisp.show document?p table=standards\&p id=9784). Information about Appendix D and voluntary use of respirators can be found on the OSHA website at https://www.osha.gov/video/respiratory_protection/voluntaryuse transcript.html.

Please be aware that N95s are not protective against alpha-diketones (diacetyl, 2,3-pentanedione, or 2,3-hexanedione). In cases of dual exposure to dust and alphadiketones, NIOSH-certified organic vapor cartridges (for the alpha-diketones) and particulate cartridges/filters (for the dust) would be warranted.

\section{Medical Monitoring}

The purpose of a medical monitoring program is to help assure the health of employees who have workplace exposures (e.g., diacetyl, 2,3-pentanedione, green coffee beans/dust) known to pose risk for potentially serious health conditions such as asthma or obliterative bronchiolitis.

1. Institute a medical monitoring program for employees who work or assist in the 
production area. The medical monitoring should consist of evaluation with a questionnaire (to obtain health and work task information) and spirometry (to assess lung function) at baseline and at one year to monitor for respiratory symptoms and to establish employees' baseline in lung function and any abnormal decline in lung function in the first year. Subsequently, an annual questionnaire evaluation should occur to monitor for respiratory symptoms. New or worsening respiratory symptoms should prompt additional evaluation including spirometry. Details about spirometry and a medical monitoring program can be found in chapter 9 of the NIOSH Criteria Document [NIOSH 2016].

2. If an employee is identified as likely having lung disease from exposure to diacetyl or 2,3-pentanedione, it should be viewed as a sentinel event indicating that there was a breakdown in exposure controls and that there is potential risk for co-workers. Should this occur, the unanticipated source of exposure must be identified and brought under control. In addition, increased intensity of medical surveillance would be required for all employees performing similar job tasks or having similar or greater potential for exposure. The NIOSH Criteria Document provides detailed guidance on responses to such sentinel events [NIOSH 2016].

\section{Smoking Cessation Program}

In a workplace with risk of occupational lung disease, prevention of smoking-related lung disease is important and makes the detection of work-related adverse effects easier. We recommend implementing a smoking cessation program to assist employees to stop smoking. The Centers for Disease Control and Prevention offers tools and resources for setting up a smoking cessation program [CDC 2017b]. 


\section{Appendix A: Tables}

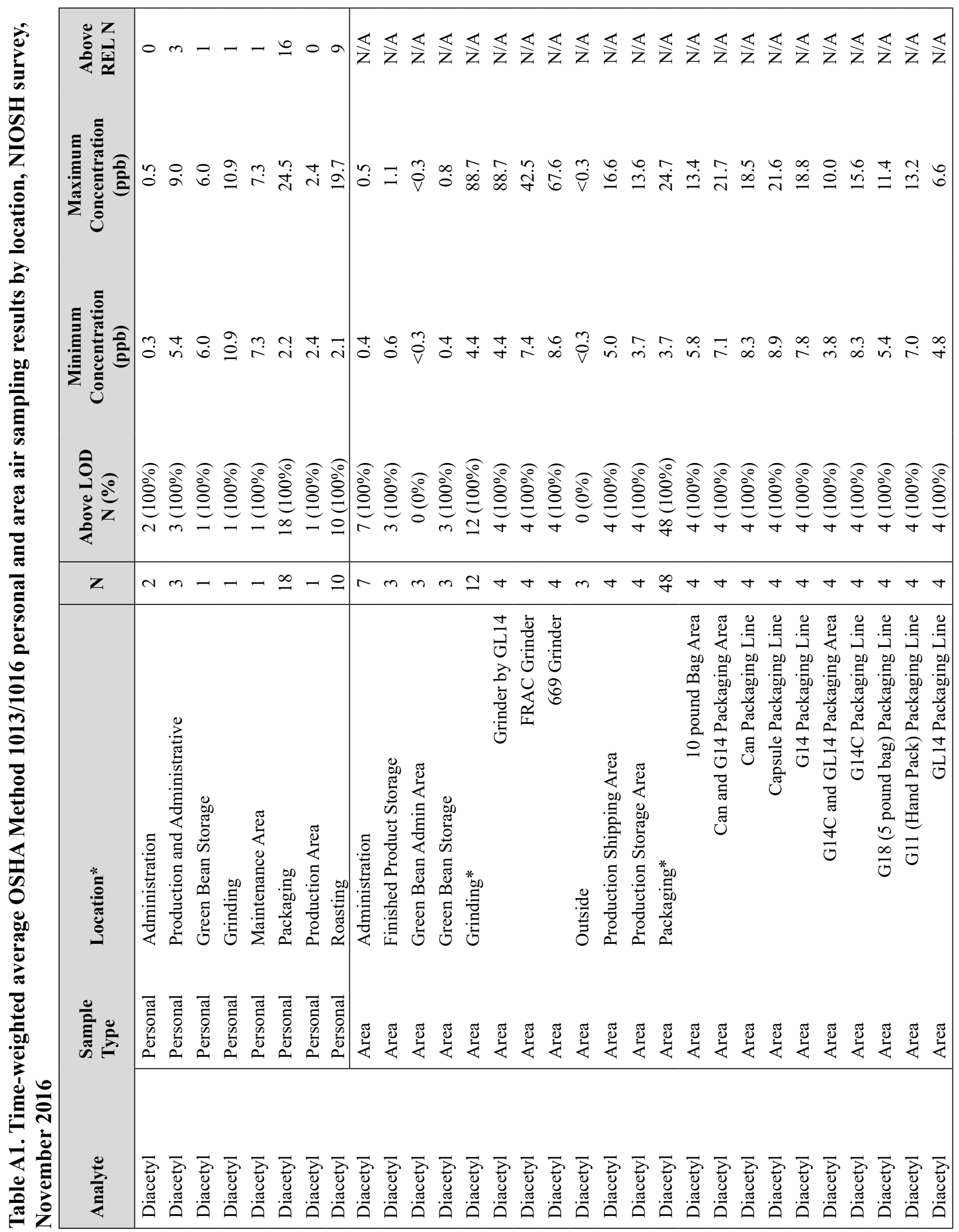




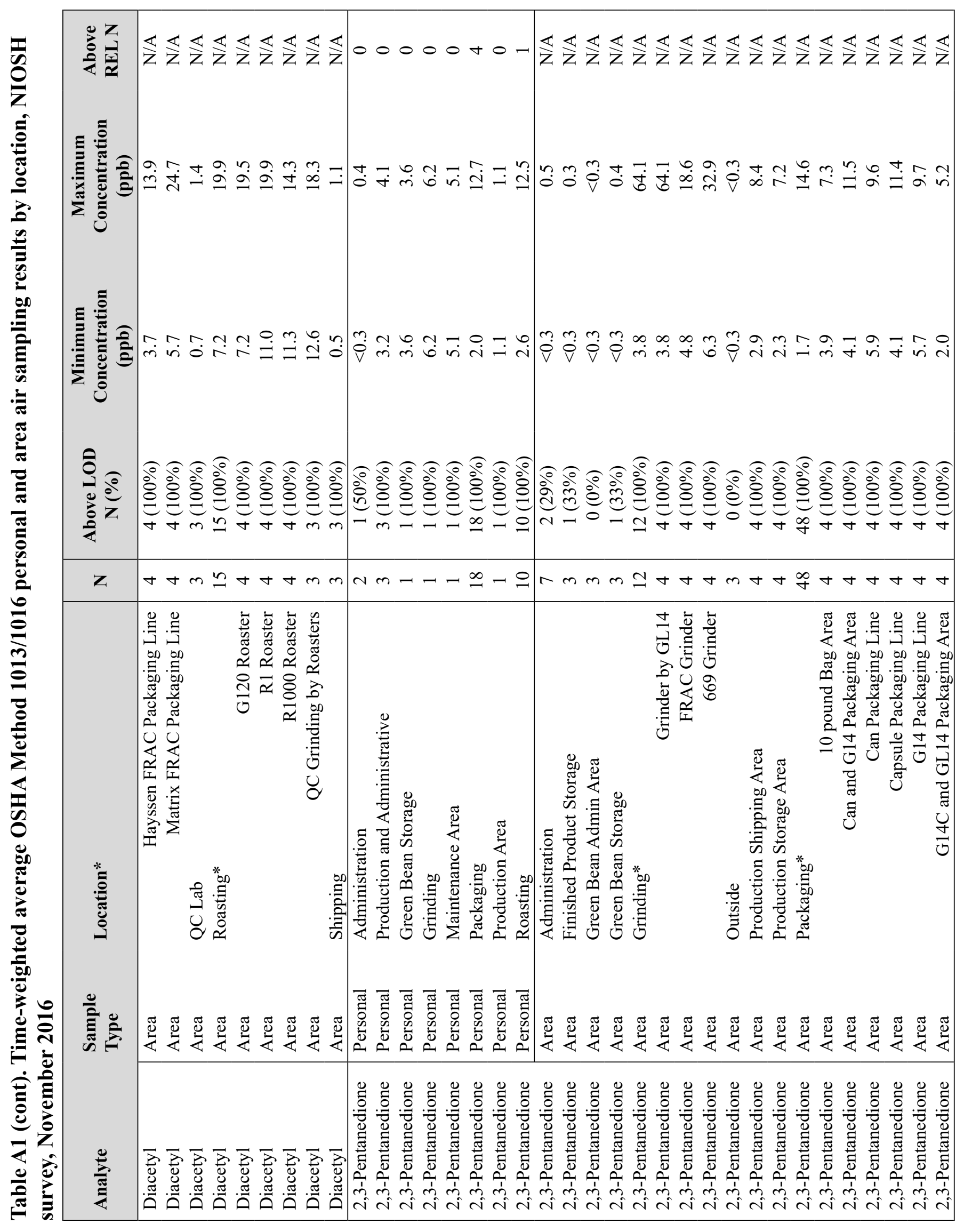




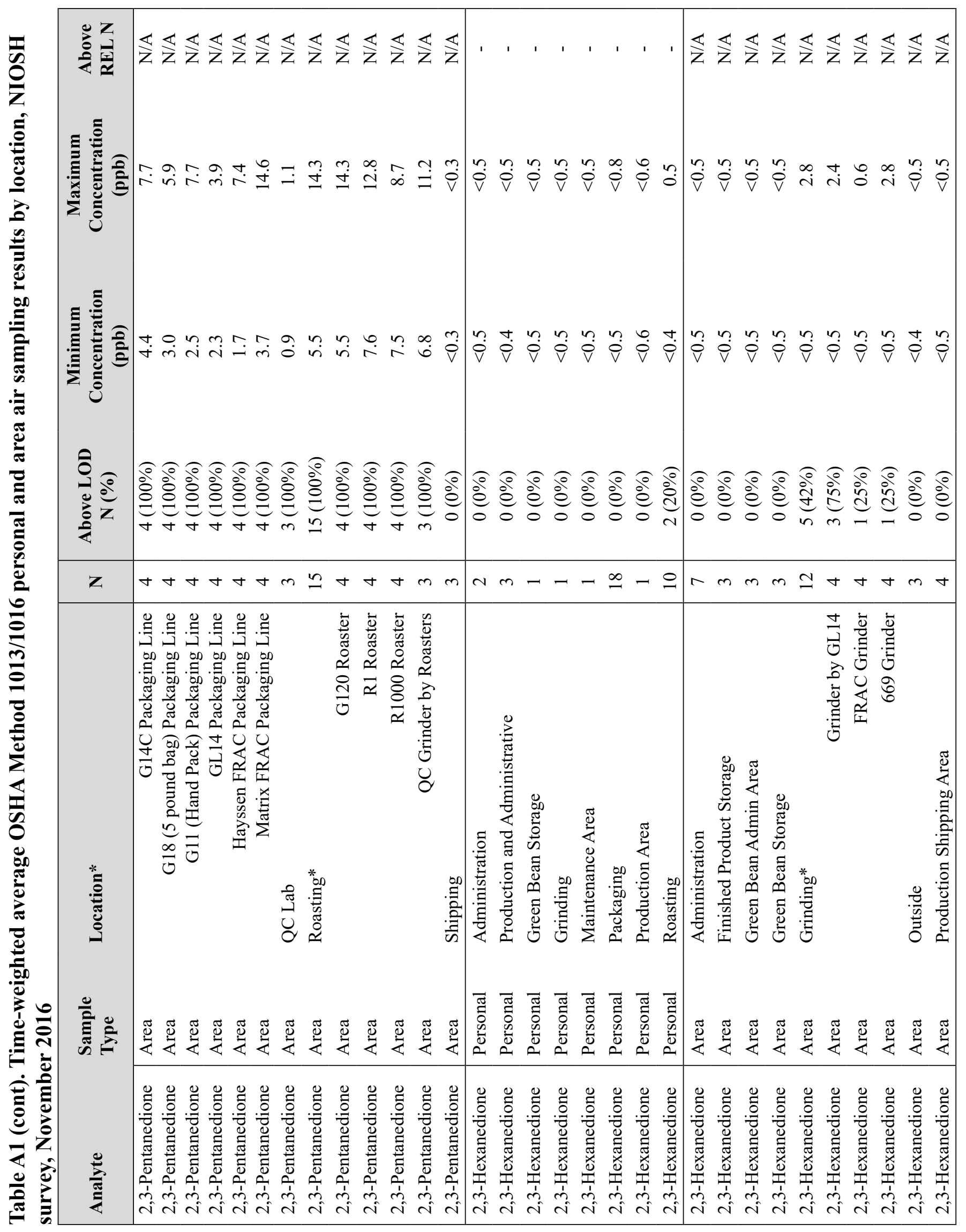




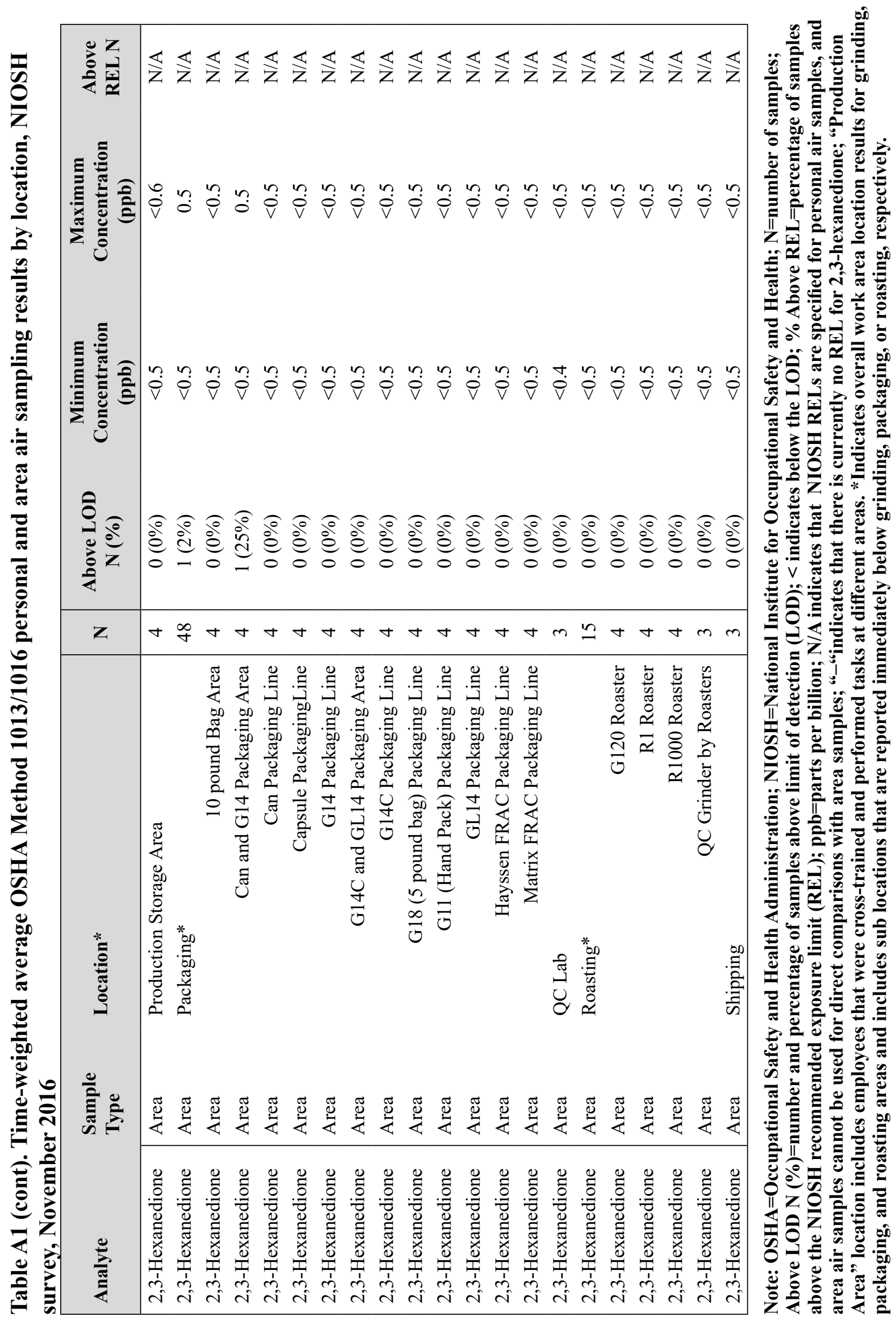




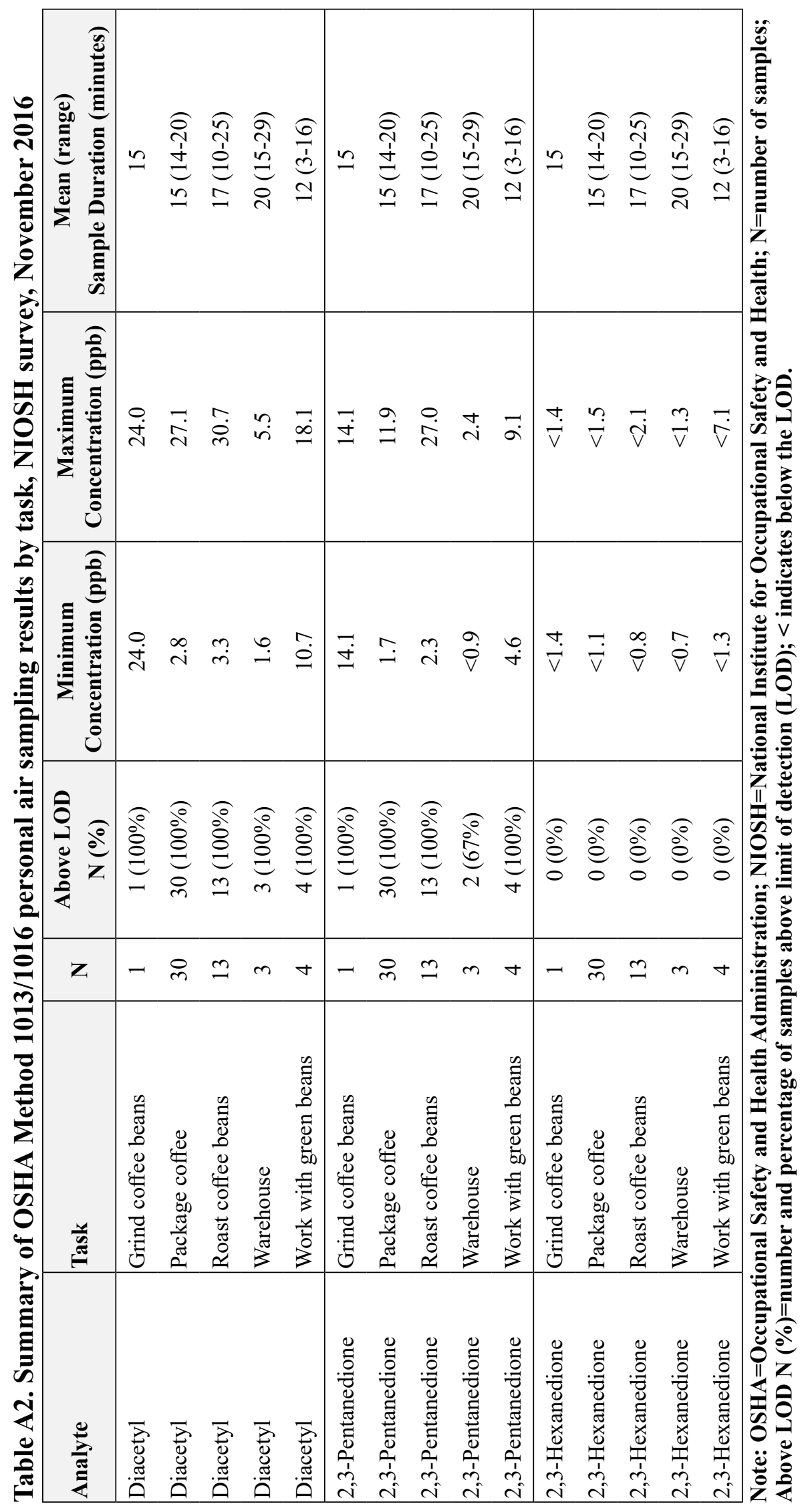


Table A3. Instantaneous evacuated canister method* air sampling results by task, NIOSH survey, November 2016

\begin{tabular}{|c|c|c|c|}
\hline Task Description & $\begin{array}{l}\text { Diacetyl } \\
\text { (ppb) }\end{array}$ & $\begin{array}{l}\text { 2,3-Pentanedione } \\
\text { (ppb) }\end{array}$ & $\begin{array}{c}\text { 2,3-Hexanedione } \\
\text { (ppb) }\end{array}$ \\
\hline Checking color of beans in roaster & 14.6 & 7.4 & $<2.5$ \\
\hline Checking color of beans in roaster & 29.0 & 12.5 & $<1.7$ \\
\hline Checking color of beans in roaster & 11.6 & 7.9 & $<1.6$ \\
\hline Dumping roasted beans from roaster into cooling bin & 13.3 & 6.9 & $<1.5$ \\
\hline Dumping green beans into hopper & 26.3 & 19.6 & 13.0 \\
\hline Dumping roasted beans from $\mathrm{G} 120$ roaster into cooling bin & 18.9 & 10.9 & $<2.0$ \\
\hline Dumping roasted beans from G120 roaster into cooling bin & 20.7 & 13.4 & 1.3 \\
\hline Dumping roasted beans from R1 roaster into cooling bin & 24.5 & 15.7 & $<1.1$ \\
\hline Dumping roasted beans from roaster into cooling bin & 30.8 & 14.1 & $<1.4$ \\
\hline Dumping roasted beans from roaster into cooling bin & 32.9 & 16.8 & $<1.9$ \\
\hline Dumping roasted beans from roaster into cooling bin & 12.8 & 8.2 & $<1.2$ \\
\hline Dumping whole beans into grinder by hand; Organic French Roast & 80.1 & 30.4 & 2.2 \\
\hline Dumping whole beans into grinder by hand; Organic French Roast & 122 & 38.0 & 1.9 \\
\hline Dumping whole beans into grinder by hand; Organic French Roast & 370 & 131 & $<12.9$ \\
\hline Filling cans with ground coffee; & 17.3 & 5.4 & $<1.2$ \\
\hline Filling cans with ground coffee; & 23.4 & 9.1 & $<1.3$ \\
\hline Grinding roasted coffee & 9.7 & 3.9 & $<1.1$ \\
\hline Grinding coffee on FRAC line & 40.9 & 27.2 & 1.7 \\
\hline Grinding coffee on FRAC line & 12.4 & 6.3 & $<1.1$ \\
\hline Grinding coffee on FRAC line & 9.4 & 4.2 & $<1.1$ \\
\hline Grinding coffee on FRAC line & 109 & 39.8 & 4.5 \\
\hline Grinding coffee on FRAC line & 23.3 & 12.7 & 5.9 \\
\hline Grinding coffee on FRAC line & 11.9 & 6.4 & $<1.1$ \\
\hline Grinding coffee on FRAC line and adding mis-weighed bags to grinder & 11.1 & 5.8 & $<1.1$ \\
\hline Grinding roasted coffee & 3.9 & $<0.6$ & $<1.1$ \\
\hline Grinding using QC grinder by roasters to check color and quality of beans & 26.3 & 11.6 & $<1.9$ \\
\hline Grinding using QC grinder by roasters to check color and quality of beans & 18.4 & 8.1 & $<1.7$ \\
\hline Grinding using QC grinder by roasters to check color and quality of beans & 8.2 & 4.8 & $<1.3$ \\
\hline Grinding using QC grinder by roasters to check color and quality of beans & 7.1 & 3.2 & $<1.4$ \\
\hline Grinding using QC grinder by roasters to check color and quality of beans & 6.6 & 4.6 & $<2.0$ \\
\hline Grinding using QC grinder by roasters to check color and quality of beans & 13.6 & 6.2 & $<1.5$ \\
\hline Grinding using QC grinder by roasters to check color and quality of beans & 41.0 & 19.7 & $<1.2$ \\
\hline Grinding using QC grinder by roasters to check color and quality of beans & 24.1 & 14.6 & $<1.6$ \\
\hline Grinding using QC grinder by roasters to check color and quality of beans & 36.6 & 22.7 & 3.8 \\
\hline Grinding using QC grinder by roasters to check color and quality of beans & 18.4 & 7.7 & $<1.1$ \\
\hline Grinding using QC grinder by roasters to check color and quality of beans & 12.5 & 7.8 & 1.5 \\
\hline
\end{tabular}

Note: NIOSH=National Institute for Occupational Safety and Health; ppb=parts per billion; < indicates below the limit of detection; $\mathrm{QC}=$ quality control. *Sampling duration approximately 30 seconds; task-based air samples were collected by placing the inlet of the canister sampler in the employee's personal breathing zone as he/she performed work task. 


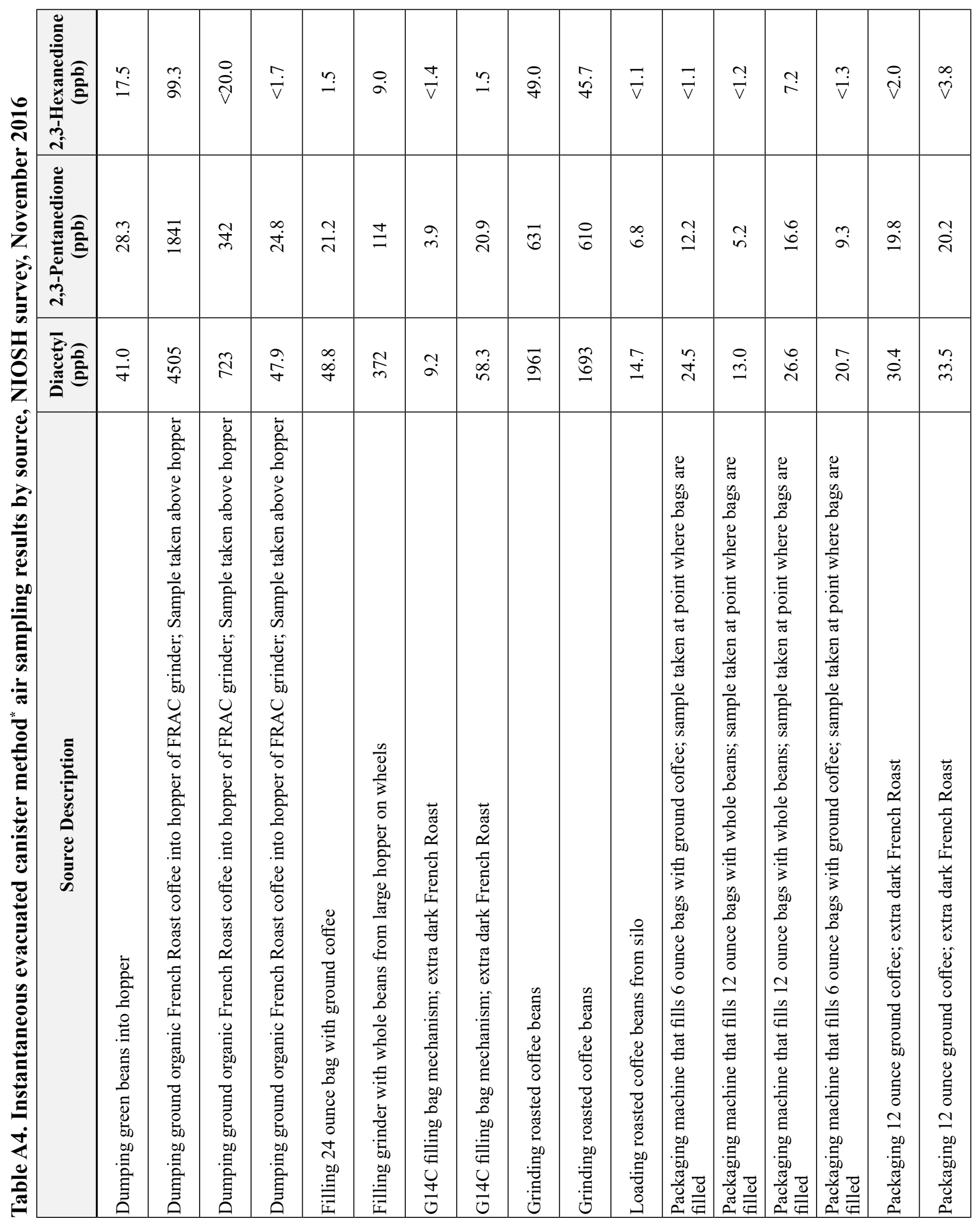




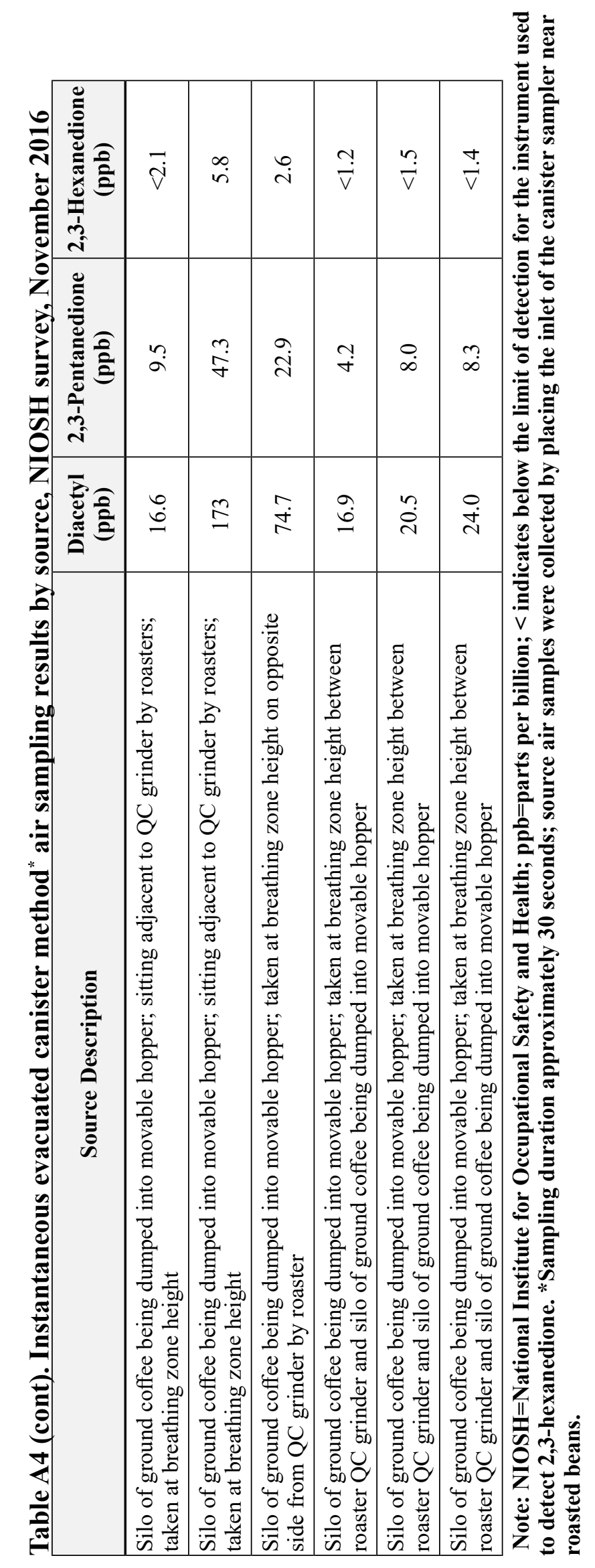


Table A5. Headspace analysis results* for bulk samples of roasted coffee beans, NIOSH survey, November 2016

\begin{tabular}{|l|l|ccc|}
\hline Sample Type & Bulk Sample Description & $\begin{array}{c}\text { Diacetyl } \\
\text { (ppb) }\end{array}$ & $\begin{array}{c}\text { 2,3-Pentanedione } \\
\text { (ppb) }\end{array}$ & $\begin{array}{c}\text { 2,3-Hexanedione } \\
\mathbf{( p p b )}\end{array}$ \\
\hline Coffee beans & Medium Roast & 10085 & 9639 & 242 \\
Coffee beans & Organic Breakfast Light Roast & 8810 & 8991 & 220 \\
Coffee beans & Extra Dark French Roast & 7066 & 2576 & 264 \\
\hline
\end{tabular}

Table A6. Summary of continuous area air monitoring results for carbon dioxide, carbon monoxide, temperature, and total volatile organic compounds, NIOSH industrial hygiene survey, November 2016

\begin{tabular}{|c|c|c|c|c|}
\hline Location & $\begin{array}{c}\mathrm{CO}_{2}(\mathrm{ppm}) \\
\text { Mean (Range) }\end{array}$ & $\begin{array}{c}\text { CO (ppm) } \\
\text { Mean (Range) }\end{array}$ & $\begin{array}{c}\text { Temperature }\left({ }^{\circ} \mathbf{F}\right) \\
\text { Mean (Range) }\end{array}$ & $\begin{array}{c}\text { Total VOC (ppb) } \\
\text { Mean (Range) }\end{array}$ \\
\hline 669 grinder & $\begin{array}{c}432 \\
(339-1118)\end{array}$ & $\begin{array}{c}7.5 \\
(3.6-117.8)\end{array}$ & $\begin{array}{c}73.1 \\
(70.4-77)\end{array}$ & $\begin{array}{c}1066 \\
(53-39164)\end{array}$ \\
\hline Grinder by GL14 & $\begin{array}{c}573 \\
(349-1076)\end{array}$ & $\begin{array}{c}17.6 \\
(3-125.9)\end{array}$ & $\begin{array}{c}80.3 \\
(70.4-84.3)\end{array}$ & $\begin{array}{c}1246 \\
(100-1246)\end{array}$ \\
\hline FRAC grinder & $\begin{array}{c}502 \\
(227-2103)\end{array}$ & $\begin{array}{c}12 \\
(<0.1-338)\end{array}$ & $\begin{array}{c}63.8 \\
(31.7-65.5)\end{array}$ & $\begin{array}{c}2049 \\
(233-16181)\end{array}$ \\
\hline Roasting QC grinder & $\begin{array}{c}415 \\
(379-561)\end{array}$ & $\begin{array}{c}7 \\
(3.2-33.1)\end{array}$ & $\begin{array}{c}78.5 \\
(71.1-83.1)\end{array}$ & $\begin{array}{c}6701 \\
(2676-46548)\end{array}$ \\
\hline G120 roaster & $\begin{array}{c}439 \\
(397-763)\end{array}$ & $\begin{array}{c}7.6 \\
(3.5-14.5)\end{array}$ & $\begin{array}{c}81.8 \\
(76.3-86.5)\end{array}$ & $\begin{array}{c}6412 \\
(2-14515)\end{array}$ \\
\hline R1000 roaster & $\begin{array}{c}414 \\
(383-505)\end{array}$ & $\begin{array}{c}6.2 \\
(3.1-14.1)\end{array}$ & $\begin{array}{c}65.4 \\
(64.2-66.5)\end{array}$ & $\begin{array}{c}5626 \\
(338-11556)\end{array}$ \\
\hline Can and G14 packaging line & $\begin{array}{c}399 \\
(367-582)\end{array}$ & $\begin{array}{c}1 \\
(<0.1-3.5)\end{array}$ & $\begin{array}{c}72.4 \\
(69.7-77.7)\end{array}$ & - \\
\hline Capsule packaging line & $\begin{array}{c}429 \\
(340-1886)\end{array}$ & $\begin{array}{c}1.9 \\
(0.2-8.4)\end{array}$ & $\begin{array}{c}79.5 \\
(68.9-89.4)\end{array}$ & - \\
\hline G14C packaging line & $\begin{array}{c}437 \\
(394-563)\end{array}$ & $\begin{array}{c}5.8 \\
(2.6-22)\end{array}$ & $\begin{array}{c}63.1 \\
(61.8-64.1)\end{array}$ & - \\
\hline
\end{tabular}

Note: NIOSH=National Institute for Occupational Safety and Health; $\mathrm{CO}_{2}=$ carbon dioxide; $\mathrm{CO}=$ carbon monoxide; ppm=parts per million; ${ }^{\circ} \mathrm{F}=$ degrees Fahrenheit; $\mathrm{VOC}=$ volatile organic compounds;

"-_indicates the measurement was not recorded. 
Table A7. Summary of continuous personal air measurements for carbon monoxide, NIOSH industrial hygiene survey, November 2016

\begin{tabular}{|c|c|c|}
\hline Job Title & Work Area & $\begin{array}{c}\text { CO (ppm) } \\
\text { Mean (range) }\end{array}$ \\
\hline Roaster Operator & Roaster & $\begin{array}{c}3.6 \\
(<0.1-118)\end{array}$ \\
\hline Roaster Operator & Roaster & $\begin{array}{c}2.7 \\
(<0.1-203)\end{array}$ \\
\hline Roaster Operator & Roaster & $\begin{array}{c}12.3 \\
(<0.1-267)\end{array}$ \\
\hline Production & Production, Packaging & $\begin{array}{c}3.8 \\
(<0.1-30)\end{array}$ \\
\hline Production & Production, Grinding & $\begin{array}{c}5.4 \\
(<0.1-75) \\
\end{array}$ \\
\hline Quality Control & All Over & $\begin{array}{c}3.0 \\
(<0.1-26) \\
\end{array}$ \\
\hline Maintenance Mechanic & Maintenance Area & $\begin{array}{c}3.2 \\
(<0.1-24)\end{array}$ \\
\hline
\end{tabular}

Note: $\mathrm{NIOSH}=$ National Institute for Occupational Safety and Health; $\mathrm{CO}=$ carbon monoxide; $\mathbf{p p m}=\mathbf{p a r t s}$ per million; < indicates below the limit of detection for the instrument used to detect carbon monoxide 


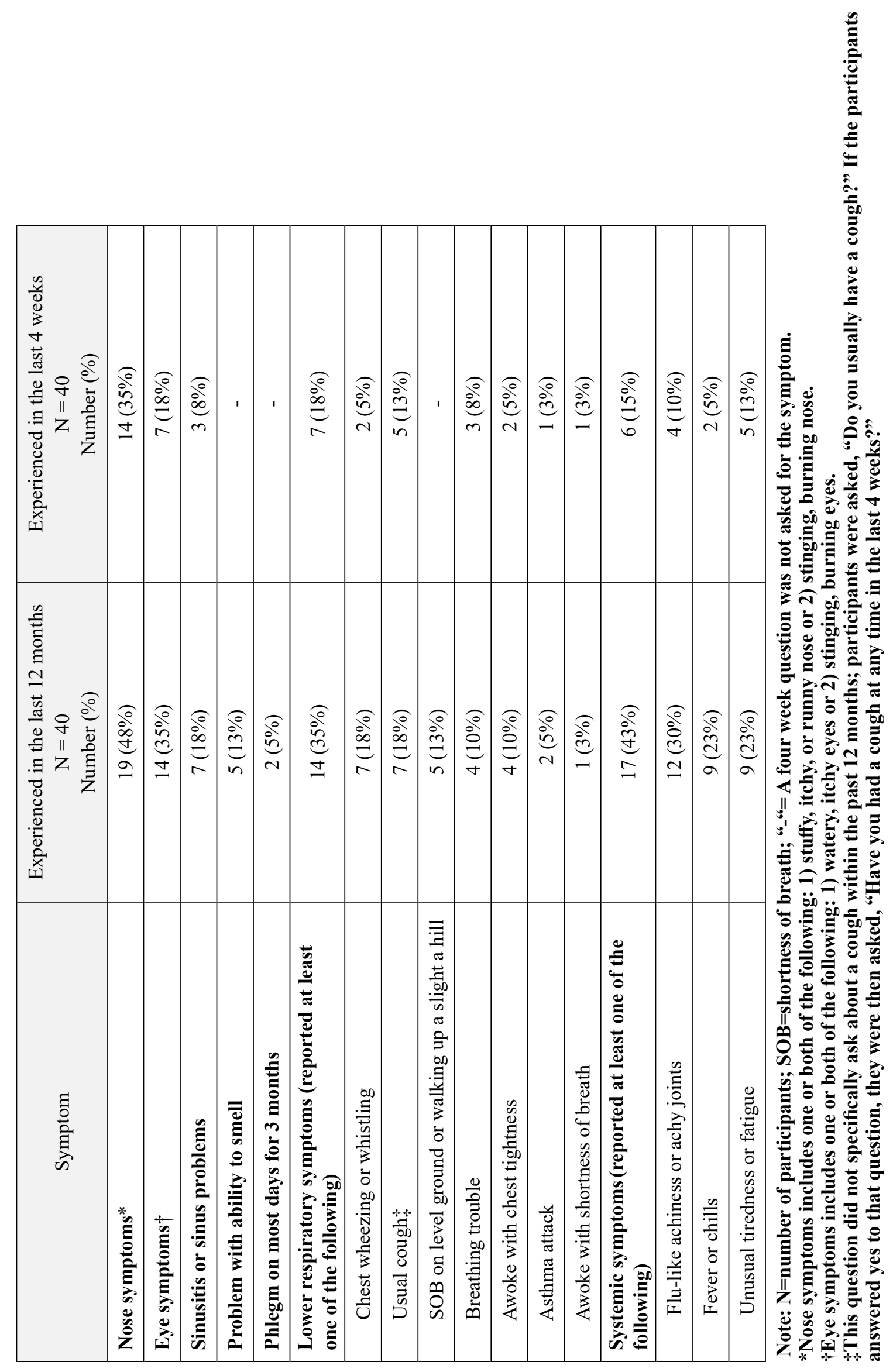




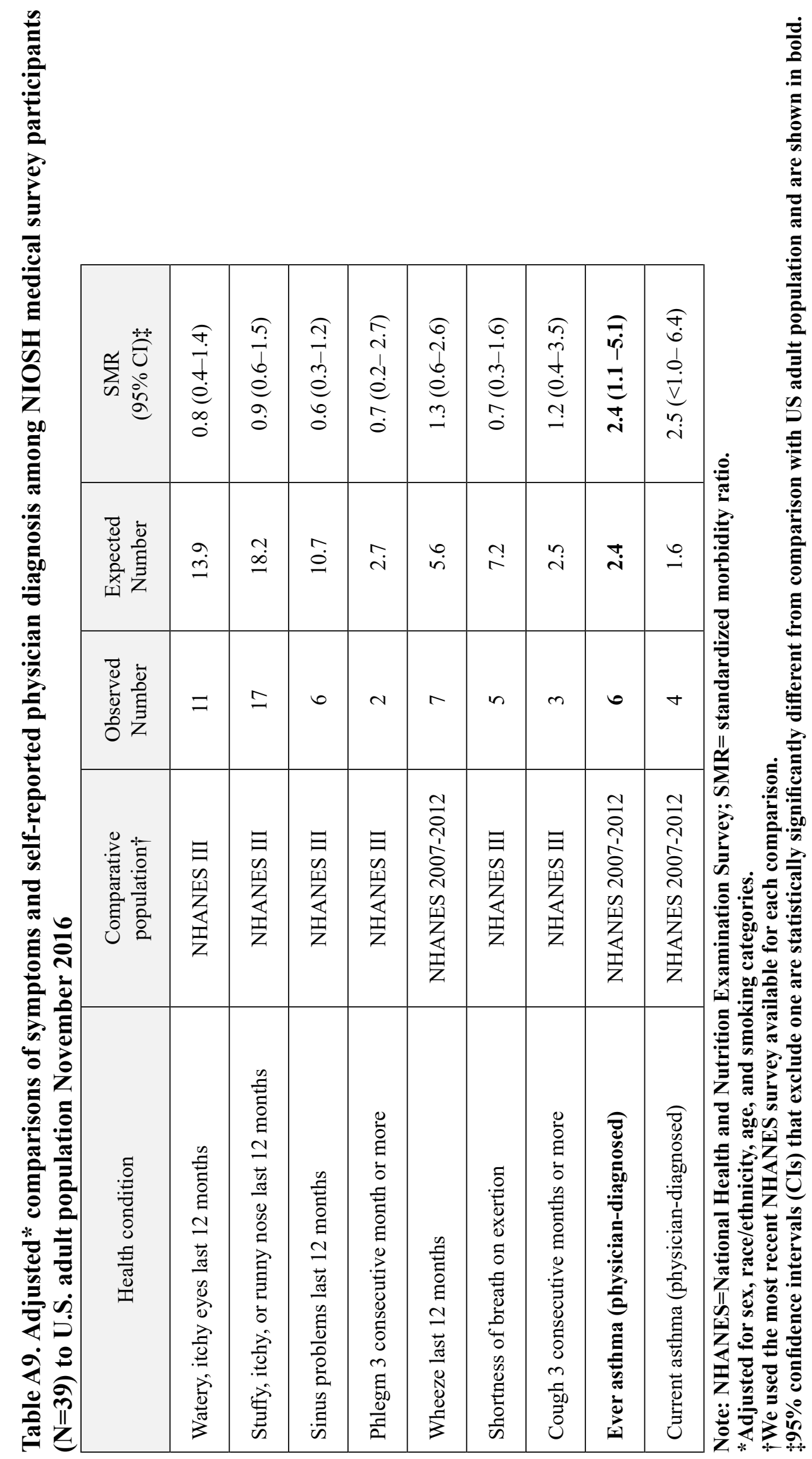




\section{References}

ACGIH (American Conference of Governmental Industrial Hygienist) [2017a]. 2017 TLVs ${ }^{\circledR}$ and BEIs ${ }^{\circledR}$ : Threshold limit values for chemical substances and physical agents and biological exposure indices. Cincinnati, $\mathrm{OH}$ : American Conference of Governmental Industrial Hygienists.

ACGIH [2017b]. Chemicals Substances and Other Issues Under Study (TLV®-CS) [http://www.acgih.org/tlv-bei-guidelines/documentation-publications-and-data/under-studylist/chemical-substances-and-other-issues-under-study-tlv]. Date accessed: February 2018.

Akiyama M, Murakami K, Ohtani N, Iwatsuki K, Sotoyama K, Wada A, Tokuno K, Iwabuchi H, Tanaka K [2003]. Analysis of volatile compounds released during the grinding of roasted coffee beans using solid-phase microextraction. J Agric Food Chem 51(7):1961-1969.

Akpinar-Elci M, Travis WD, Lynch DA, Kreiss K [2004]. Bronchiolitis obliterans syndrome in popcorn production plant workers. Eur Respir J 24(2):298-302.

Anderson BA, Shimoni E, Liardon R, Labuza P [2003]. The diffusion kinetics of carbon dioxide in fresh roasted and ground coffee. J Food Eng 59:71-78.

Bailey RL, Cox-Ganser JM, Duling MG, LeBouf RF, Martin SB Jr, Bledsoe TA, Green BJ, Kreiss K [2015]. Respiratory morbidity in a coffee processing workplace with sentinel obliterative bronchiolitis cases. Am J Ind Med 58(12):1235-1245.

Berger KI, Reibman J, Oppenheimer BW, Vlahos I, Harrison D, Goldring RM [2013]. Lessons from the World Trade Center disaster: airway disease presenting as restrictive dysfunction. Chest 144(1):249-257.

Burney PGJ, Chinn S [1987]. Developing a new questionnaire for measuring the prevalence and distribution of asthma. Chest 91(6 Suppl):79S-83S.

Burney PG, Laitinen LA, Perdrizet S, Huckauf H, Tattersfield AE, Chinn S, Poisson N, Heeren A, Britton JR, Jones T [1989]. Validity and repeatability of the IUATLD (1984) Bronchial symptoms questionnaire: an international comparison. Eur Respir J 2(10):940-945.

Burney PGJ, Luczynska C, Chinn S, Jarvis D [1994]. The European community respiratory health survey. Eur Respir J 7(5):954-960.

CDC (Centers for Disease Control and Prevention) [1996]. Third National Health and Nutrition Examination Survey, 1988-1994, NHANES III Examination Data File [CDROM]. Hyattsville, Maryland: U.S. Department of Health and Human Services, Centers for Disease Control and Prevention. (Public use data file documentation No. 76300.) 
CDC [2013a]. Carbon monoxide [https://www.cdc.gov/niosh/topics/co-comp/default.html]. Date accessed: February 2018.

CDC [2013b]. Obliterative bronchiolitis in workers in a coffee-processing facility-Texas, 2008-2012. Morb Mortal Wkly Rep 62(16):305-307.

CDC [2017a]. National Center for Health Statistics. National Health and Nutrition Examination Survey Data. Hyattsville, MD: U.S. Department of Health and Human Services, Centers for Disease Control and Prevention, [2007-2012] Available at: https://wwwn.cdc. gov/nchs/nhanes/default.aspx. Date accessed: February 2018.

CDC [2017b]. Smoking \& tobacco use: quit smoking [https://www.cdc.gov/tobacco/stateandcommunity/tobacco control programs/index.htm]. Date accessed: February 2018.

CFR. Code of Federal Regulations. Washington, DC: U.S. Government Printing Office, Office of the Federal Register.

Daglia M, Papetti A, Aceti C, Sordelli B, Spini V, Gazzani G [2007]. Isolation and determination of $\alpha$-dicarbonyl compounds by RP-HPLC-DAD in green and roasted coffee. $\mathrm{J}$ Agric and Food Chem 55(22):8877-8882.

Day G, LeBouf R, Grote A, Pendergrass S, Cummings K, Kreiss K, and Kullman G [2011]. Identification and measurement of diacetyl substitutes in dry bakery mix production. J Occ Env Hygiene 8(2):93-103.

de Assumpção MS, Gonçalves RM, Martins R, Bobbio TG, Schivinski CI [2016]. Reference equations for impulse oscillometry system parameters in healthy Brazilian children and adolescents. Respir Care 61(8):1090-1099.

Desiraju K, Agrawal A [2016]. Impulse oscillometry: The state-of-art for lung function testing. Lung India 33(4):410-416.

Duling MG, LeBouf RF, Cox-Ganser JM, Kreiss K, Martin SB Jr, Bailey RL [2016]. Environmental characterization of a coffee processing workplace with obliterative bronchiolitis in former workers. J Occup Environ Hyg 13(10):770-781.

Dweik RA, Boggs PB, Erzurum SC, Irvin CG, Leigh MW, Lundberg JO, Olin AC, Plummer AL, Taylor DR; American Thoracic Society Committee on Interpretation of Exhaled Nitric Oxide Levels (FENO) for Clinical Applications [2011]. An official ATS clinical practice guideline: interpretation of exhaled nitric oxide levels (FENO) for clinical applications. Am J Respir Crit Care Med 184(5):602-615.

ECRHS (European Community Respiratory Health Survey) [2014]. Questionnaires, protocols and instructions [http://www.ecrhs.org/Quests.htm]. Date accessed: February 2018. 
EAACI Task Force on Occupational Rhinitis, Moscato G, Vandenplas O, Gerth Van Wijk R, Malo JL, Quirce S, Walusiak J, Castano R, De Groot H, Folletti I, Gautrin D, Yacoub MR, Perfetti L, Siracusa A [2008]. Occupational rhinitis. Allergy 63(8):969-980.

Ferris BG [1978]. Epidemiology standardization project. AmRev Respir Dis 118(Suppl):1-53.

Figley KD, Rawling FF [1950] Castor bean: an industrial hazard as a contaminant of green coffee dust and used burlap bags. J Allergy 21:545-553.

Hankinson JL, Odencrantz JR, Fedan KB [1999]. Spirometric reference values from a sample of the general U.S. population. Am J Respir Crit Care Med 159(1):179-187.

Henneberger PK, Redlich CA, Callahan DB, Harber P, Lemière C, Martin J, Tarlo SM, Vandenplas O, Torén K; ATS Ad Hoc Committee on Work-Exacerbated Asthma [2011]. An official American Thoracic Society statement: work-exacerbated asthma. Am J Respir Crit Care Med 184(3):368-378.

Hubbs AF, Cumpston AM, Goldsmith WT, Battelli LA, Kashon ML, Jackson MC, Frazer DG, Fedan JS, Goravanahally MP, Castranova V, Kreiss K, Willard PA, Friend S, SchweglerBerry D, Fluharty KL, Sriram K [2012]. Respiratory and olfactory cytotoxicity of inhaled 2,3-pentanedione in Sprague-Dawley rats. Am J Pathol 181(3):829-844.

Kanwal R, Kullman G, Piacitelli C, Boylstein R, Sahakian N, Martin S, Fedan K, Kreiss K [2006]. Evaluation of flavorings-related lung disease risk at six microwave popcorn plants. J Occup Environ Med. 48(2):149-57.

Karr RM, Davies RJ, Butcher BT, Lehrer SB, Wilson MR, Dharmarajan V, Salvaggio JE [1978]. Occupational asthma. J Allergy Clin Immunol 61(1):54-65.

Kim TJ, Materna BL, Prudhomme JC, Fedan KB, Enright PL, Sahakian NM, Windham GC, Kreiss K [2010]. Industry-wide medical surveillance of California flavor manufacturing workers: Cross-sectional results. Am J Ind Med 53(9):857-865.

King MS, Eisenberg R, Newman JH, Tolle JJ, Harrell FE Jr, Nian H, Ninan M, Lambright ES, Sheller JR, Johnson JE, Miller RF [2011]. Constrictive bronchiolitis in soldiers returning from Iraq and Afghanistan. N Engl J Med. 365(3):222-230.

Kreiss K [2013]. Occupational causes of constrictive bronchiolitis. Curr Opin Allergy Clin Immunol 13(2):167-172.

Komarow HD, Myles IA, Uzzaman A, Metcalfe DD [2011]. Impulse oscillometry in the evaluation of diseases of the airways in children. Ann Allergy Asthma Immunol 106(3):191199. 
Langford NJ [2005]. Carbon dioxide poisoning. Toxicol Rev 24(4):229-235.

LeBouf RF, Stefaniak AB, Virji, MA [2012]. Validation of evacuated canisters for sampling volatile organic compounds in healthcare settings. J Environ Monit 14(3):977-983.

LeBouf RF and Simmons M [2017]. Increased sensitivity of OSHA method analysis of diacetyl and 2,3-pentanedione in air. J Occup Environ Hyg 14(5):343-348.

Lee JY, Seo JH, Kim HY, Jung YH, Kwon JW, Kim BJ, Kim HB, Lee SY, Jang GC, Song DJ, Kim WK, Shim JY, Kim HJ, Shin YJ, Park JW, Cho SH, Lee JS, Hong SJ [2012]. Reference values of impulse oscillometry and its utility in the diagnosis of asthma in young Korean children. J Asthma 49(8):811-816.

Lehrer SB, Karr RM, Salvaggio JE [1978]. Extraction and analysis of coffee bean allergens. Clin Allergy 8(3):217-226.

Malmberg LP, Pelkonen A, Poussa T, Pohianpalo A, Haahtela T, Turpeinen M [2002]. Determinants of respiratory system input impedance and bronchodilator response in healthy Finnish preschool children. Clin Physiol Funct Imaging 22(1):64-71.

Miller MR, Hankinson J, Brusasco V, Burgos F, Casaburi R, Coates A, Crapo R, Enright P, van der Grinten CP, Gustafsson P, Jensen R, Johnson DC, MacIntyre N, McKay R, Navajas D, Pedersen OF, Pellegrino R, Viegi G, Wanger J, ATS/ERS Task Force [2005]. Standardisation of spirometry. Eur Respir J 26(2):319-338.

Morgan DL, Jokinen MP, Price HC, Gwinn WM, Palmer SM, Flake GP [2012]. Bronchial and bronchiolar fibrosis in rats exposed to 2,3-pentanedione vapors: implications for bronchiolitis obliterans in humans. Toxicol Pathol 40(3):448-465.

Morgan DL, Jokinen MP, Johnson CL, Price HC, Gwinn WM, Bousquet RW, Flake GP [2016]. Chemical reactivity and respiratory toxicity of the $\alpha$-diketone flavoring agents: 2,3-butanedione, 2,3-pentanedione, and 2,3-hexanedione. Toxicol Pathol 44(5):763-783.

Newbury W, Crockett A, Newbury J [2008]. A pilot study to evaluate Australian predictive equations for the impulse oscillometry system. Respirology 13(7):1070-1075.

Newton J [2002]. Carbon monoxide exposure from coffee roasting. Appl Occup Environ Hyg. 17(9):600-602.

NIOSH (National Institute for Occupational Safety and Health) [2003]. NIOSH manual of analytical methods (NMAM $\left.{ }^{\circledR}\right)$. 4th ed. Schlecht PC, O'Connor PF, eds. Cincinnati, OH: U.S. Department of Health and Human Services, Centers for Disease Control and Prevention, National Institute for Occupational Safety and Health, DHHS (NIOSH) Publication 94-113 (August 1994); 1st Supplement Publication 96-135, 2nd Supplement Publication 98-119; 3rd Supplement 2003-154 [http://www.cdc.gov/niosh/docs/2003-154/]. Date accessed: February 2018. 
NIOSH (2004). NIOSH respirator selection logic. Department of Health and Human Services, Centers for Disease Control and Prevention, National Institute for Occupational Safety and Health DHHS (NIOSH) Publication No. 2005-100 [https:/www.cdc.gov/niosh/ docs/2005-100/pdfs/2005-100.pdf]. Date accessed: February 2018.

NIOSH [2010]. NIOSH pocket guide to chemical hazards. Cincinnati, OH: U.S. Department of Health and Human Services, Centers for Disease Control and Prevention, National Institute for Occupational Safety and Health, DHHS (NIOSH) Publication No. 2010-168c [http://www.cdc.gov/niosh/npg/]. Date accessed: February 2018.

NIOSH [2012]. Flavoring-related lung disease. Information for healthcare providers. Department of Health and Human Services, Centers for Disease Control and Prevention, DHHS (NIOSH) Publication No. 2012-148 (supersedes 2012-107) [http://www.cdc.gov/ niosh/docs/2012-148/]. Date accessed: February 2018.

NIOSH [2016]. Criteria for a recommended standard: occupational exposure to diacetyl and 2,3-pentanedione. U.S. Department of Health and Human Services, Centers for Disease Control and Prevention, National Institute for Occupational Safety and Health, DHHS (NIOSH) Publication No. 2016-111. [https://www.cdc.gov/niosh/docs/2016-111/]. Date accessed: February 2018.

Nishimura F, Abe S, Fukunaga T [2003]. Carbon monoxide poisoning from industrial coffee extraction. JAMA 290(3):334.

Oldenburg M, Bittner C, Baur X [2009]. Health risks due to coffee dust. Chest 136(2):536544

OSHA (Occupational Safety and Health Administration) [1993]. Compliance and enforcement activities affected by the PELs decision. August 5, 1993 Memorandum. [https:// www.osha.gov/pls/oshaweb/owadisp.show document?p table=INTERPRETATIONS\&p $\underline{\mathrm{id}=21220]}$. Date accessed: February 2018.

OSHA [2003]. Enforcement policy for respiratory hazards not covered by OSHA permissible exposure limits. January 24, 2003 Memorandum. [https://www.osha.gov/pls/oshaweb/ owadisp.show document?p table=INTERPRETATIONS\&p_id=24749]. Date accessed: February 2018.

OSHA [2008]. Sampling and analytical methods: Method 1013 - Acetoin and diacetyl [http:// www.osha.gov/dts/sltc/methods/validated/1013/1013.html]. Date accessed: February 2018.

OSHA [2010]. Sampling and analytical methods: Method 1016 - 2,3-pentanedione [http:// www.osha.gov/dts/sltc/methods/validated/1016/1016.html]. Date accessed: February 2018.

OSHA [2014]. OSHA Fact sheet: Do you have work-related asthma? A guide for you and your doctor. Washington, D.C.: U.S. Department of Labor, Occupational Safety and Health 
Administration [https://www.osha.gov/Publications/OSHA3707.pdf]. Date accessed: February 2018.

OSHA [2016]. Permissible exposure limits - annotated tables [https://www.osha.gov/dsg/annotated-pels/index.html]. Date accessed: February 2018.

Park JH, Yoon JW, Shin YH, Jee HM, Wee YS, Chang SJ, Sim JH, Yum HY, Han MY [2011]. Reference values for respiratory system impedence using impulse oscillometry in healthy preschool children. Korean J Pediatr 54(2)64-68.

Pellegrino R, Viegi G, Brusasco V, Crapo RO, Burgos F, Casaburi R, Coates A, van der Grinten CP, Gustafsson P, Hankinson J, Jensen R, Johnson DC, MacIntyre N, McKay R, Miller MR, Navajas D, Pedersen OF, Wanger J [2005]. Interpretative strategies for lung function tests. Eur Respir J 26(5):948-968.

Raffel JB, Thompson J [2013]. Carbon monoxide from domestic coffee roasting: a case report. Ann Intern Med 159(11):795-796.

Rondón C, Campo P, Galindo L, Blanca-López N, Cassinello MS, Rodriguez-Bada JL, Torres MJ, Blanca M [2012]. Prevalence and clinical relevance of local allergic rhinitis. Allergy. 67(10):1282-1288.

Rondón C, Bogas G, Barrionuevo E, Blanca M, Torres MJ, Campo P [2017]. Nonallergic rhinitis and lower airway disease. Allergy 72(1):24-34.

Rose JJ, Wang L, Xu Q, McTiernan CF, Shiva S, Tejero J, Gladwin MT [2017]. Carbon monoxide poisoning: pathogenesis, management, and future directions of therapy. Am J Respir Crit Care Med 195(5):596-606.

Sahay S, Gera K, Bhargava SK, Shah A [2016]. Occurrence and impact of sinusitis in patients with asthma and/or allergic rhinitis. J Asthma 53(6):635-643.

Sakwari G, Mamuya SH, Bråtveit M, Moen BE [2013]. Respiratory symptoms, exhaled nitric oxide, and lung function among workers in Tanzanian coffee factories. J Occup Environ Med 55(5):544-551.

Schulz H, Flexeder C, Behr J, Heier M, Holle R, Huber RM, Jörres RA, Nowak D, Peters A, Wichmann HE, Heinrich J, Karrasch S; KORA Study Group [2013]. Reference values of impulse oscillometric lung function indices in adults of advanced age. PLoS One 8(5):e63366. doi: 10.1371/journal.pone.0063366.

Schulze J, Biedebach S, Christmann M, Herrmann E, Voss S, Zielen S [2016]. Impulse oscillometry as a predictor of asthma exacerbations in young children. Respiration 91(2):107114. 
Shaaban R, Zureik M, Soussan D, Neukirch C, Heinrich J, Sunyer J, Wjst M, Cerveri I, Pin I, Bousquet J, Jarvis D, Burney PG, Neukirch F, Leynaert B [2008]. Rhinitis and onset of asthma: a longitudinal population-based study. Lancet. 372(9643):1049-1057.

Shi Y, Aledia AS, Tatavoosian AV, Vijayalakshmi S, Galant SP, George SC [2012]. Relating small airways to asthma control by using impulse oscillometry in children.

Allergy Clin Immunol 129(3):671-678.

Smith HJ, Reinhold P, Goldman MD [2005]. Forced oscillation technique and impulse oscillometry. In: Gosselink R, Stam H, eds. European Respiratory Monograph 31: Lung Function Testing. Vol. 10. Wakefield, UK: European Respiratory Society Journals, pp. 72 105.

Smith HJ (Hans-Juergen.Smith@CareFusion.com) [2015]. Questions about impulse oscillometry. Email of December 9, 2015, from Hans-Juergen Smith, CareFusion, to Rachel Bailey (feu2@cdc.gov), Respiratory Health Division, National Institute for Occupational Safety and Health, Centers for Disease Control and Prevention, Department of Health and Human Services.

Song TW, Kim KW, Kim ES, Park JW, Sohn MH, Kim KE [2008]. Utility of impulse oscillometry in young children with asthma. Pediatr Allergy Immunol 19(8):763-768.

Tarlo SM, Lemiere C [2014]. Occupational asthma. N Engl J Med 370:640-649.

Tarlo SM [2016]. Update on work-exacerbated asthma. Int J Occup Med Environ Health 29(3):369-374.

Thomas KE, Trigg CJ, Baxter PJ, Topping M, Lacey J, Crook B, Whitehead P, Bennett JB, Davies RJ [1991]. Factors relating to the development of respiratory symptoms in coffee process workers. Br J Ind Med 48(5):314-322.

Vogel J, Smidt U [1994] Impulse oscillometry. Analysis of lung mechanics in general practice and clinic, epidemiological and experimental research. $1^{\text {st }}$ ed. Frankfurt: PMIVerlagsgruppe.

Weinstein DJ, Hull JE, Ritchie BL, Hayes JA, Morris MJ [2016]. Exercise-associated excessive dynamic airway collapse in military personnel. Ann Am Thorac Soc 13(9):14761482.

Zuskin E, Valić F, Skurić Z [1979]. Respiratory function in coffee workers. Br J Ind Med 36(2):117-122.

Zuskin E, Kanceljak B, Skurić Z, Butković D [1985]. Bronchial reactivity in green coffee exposure. Br J Ind Med 42(6):415-420. 
Zuskin E, Schachter EN, Kanceljak B, Witek TJ Jr, Fein E [1993]. Organic dust disease of airways. Int Arch Occup Environ Health 65(2):135-140. 
This page left intentionally blank 
Keywords: NAICS 311920 (Coffee roasting), Colorado, diacetyl, 2,3-pentanedione, 2,3-hexanedione, coffee, carbon monoxide, carbon dioxide, volatile organic compounds (VOCs). 
The Health Hazard Evaluation Program investigates possible health hazards in the workplace under the authority of the Occupational Safety and Health Act of 1970 (29 U.S.C. $§ 669$ (a) (6)). The Health Hazard Evaluation Program also provides, upon request, technical assistance to federal, state, and local agencies to investigate occupational health hazards and to prevent occupational disease or injury. Regulations guiding the Program can be found in Title 42, Code of Federal Regulations, Part 85; Requests for Health Hazard Evaluations (42 CPR Part 85).

\section{Disclaimer}

The recommendations in this report are made on the basis of the findings at the workplace evaluated and may not be applicable to other workplaces.

Mention of any company or product in this report does not constitute endorsement by the National Institute for Occupational Safety and Health (NIOSH).

Citations to Web sites external to NIOSH do not constitute NIOSH endorsement of the sponsoring organizations or their programs or products. NIOSH is not responsible for the content of these Web sites. All Web addresses referenced in this document were accessible as of the publication date.

\section{Acknowledgments}

Desktop Publisher: Tia McClelland

Data Analysis Support: Nicole Edwards, Kathleen Fedan, and Brian Tift

Laboratory Support: Dru Burns, Kyle Hatcher, Ryan LeBouf, Anand Ranpara

Site Visit Team Members: Mike Beaty, Randy Boylstein, Nicole Edwards, Reid Harvey, Brie Hawley, Stephen Martin, Jr., Tia McClelland, Jason Ham, and Michael Humann

\section{Availability of Report}

Copies of this report have been sent to the employer, employees, and union at the facility. The state and local health department and the Occupational Safety and Health Administration Regional Office have also received a copy. This report is not copyrighted and may be freely reproduced.

This report is available at http://www.cdc.gov/niosh/hhe/reports/pdfs/2016-0144-3305.pdf.

All other Health Hazard Evaluation Reports may be found at http://www2a.cdc.gov/hhe/ search.asp

Recommended citation for this report:

NIOSH [2018]. Health hazard evaluation report: Evaluation of exposures and respiratory health at a coffee roasting and packaging facility. By Harvey RR, Hawley

B, Martin SB. Morgantown, WV: U.S. Department of Health and Human Services, Centers for Disease Control and Prevention, National Institute for Occupational Safety and Health, NIOSH HHE Report No. 2016-0144-3305. 
Delivering on the Nation's promise:

Safety and health at work for all people through research and prevention

To receive documents or other information about occupational safety and health topics, contact NIOSH

Telephone: 1-800-CDC-INFO (1-800-232-4636)

TTY: 1-888-232-6348

email: cdcinfo@cdc.gov

or visit the NIOSH website at http://www.cdc.gov/niosh

SAFER • HEALTHIER $\cdot$ PEOPLE $^{\text {TM }}$ 